\title{
Investigation on the Anisotropy of Mechanical Properties and Brittleness Characteristics of Deep Laminated Sandstones
}

Mingyang Zhai ( $\square$ zhaimingyang_2011@163.com )

Northeastern University https://orcid.org/0000-0001-6755-2377

\section{Zenglin Wang}

Sinopec Shengli Oilfield

Liaoyuan Zhang

Sinopec Shengli Oilfield

Aishan Li

Sinopec Shengli Oilfield

\section{Zilin Zhang}

Sinopec Shengli Oilfield

\section{Bintao Zheng}

Sinopec Shengli Oilfield

\section{Bo Huang}

Sinopec Shengli Oilfield

\section{Lianchong Li}

Northeastern University

\section{Research Article}

Keywords: Deep laminated sandstone, Brittleness index, Anisotropy, Mechanical property, Numerical simulation, Acoustic emission

Posted Date: July 9th, 2021

DOl: https://doi.org/10.21203/rs.3.rs-660247/v1

License: (c) (i) This work is licensed under a Creative Commons Attribution 4.0 International License. Read Full License 


\title{
Investigation on the anisotropy of mechanical properties and brittleness
}

\section{characteristics of deep laminated sandstones}

\author{
Mingyang Zhai ${ }^{1}$, Zenglin Wang ${ }^{2}$, Liaoyuan Zhang ${ }^{2}$, Aishan $\mathrm{Li}^{2}$, Zilin Zhang ${ }^{2}$, Bintao Zheng ${ }^{2}$, Bo Huang ${ }^{2}$, \\ Lianchong $\mathrm{Li}^{1 *}$ \\ 1 Center of Rock Instability and Seismicity Research, School of Resources and Civil Engineering, \\ Northeastern University, Shenyang 110819, China \\ 2 Shengli Oilfield Branch Company, SINOPEC, Dongying 257000, China
}

\begin{abstract}
Rock brittleness is a crucial mechanical property and essential for fracability evaluation and fracturing scheme design in unconventional reservoirs. However, the influence of inherent anisotropy on deep laminated sandstone's mechanical properties and brittleness characteristics is rarely investigated. The energy transformation and damage evolution reflected by complete stress-strain curves are analyzed during the entire process of rock rupture under compressions. A new brittleness index is established based on energy evolution during sandstone failure. Its advantages involve comprehensively considering the energy transformation characteristics at both pre-peak and post-peak stages and the capability to characterize the effect of confining pressure and bedding plane (BP) geometry on sandstone brittleness. The triaxial compression tests on sandstones are conducted to validate the reliability and accuracy of the new brittleness index. Numerical simulations are then performed to further investigate the manner in which BP angle, BP density, and confining pressure control the brittleness anisotropy of deep laminated sandstones based on the finite element method. Then the acoustic emission (AE) characteristics of anisotropic sandstone and correlations between AE mode and brittleness index are discussed. The results indicated that the anisotropy of mechanical properties and brittleness of deep laminated sandstones were significantly affected by BP angle, BP density, and confining pressure. With the increase of BP angle, the brittleness index of deep laminated sandstone decreases first and then increases, showing a U-shape variation law, whose maximum and minimum values are obtained at $\varphi=0^{\circ}$ and $\varphi=45^{\circ}$, respectively. The AE characteristics were closely related to rock brittleness, which was jointly controlled by $\mathrm{BP}$ geometry and confining pressure. The results provide a basis for the brittleness and fracability evaluation and optimum hydraulic fracturing design in deep laminated sandstones.
\end{abstract}

Keywords: Deep laminated sandstone; Brittleness index; Anisotropy; Mechanical property; Numerical simulation; Acoustic emission

\section{Introduction}

Sedimentary rocks, normally characterized by bedding planes and significant anisotropy, are extensively distributed on the Earth (Li et al., 2016, Zhao et al., 2019, Barton and Quadros, 2015). Most reservoirs are sedimentary rocks with complex bedding structures, such as shales, sandstones, and coals. Anisotropic features may influence the mechanical and hydraulic behaviors of rock, which vary in different directions (Khanlari et al., 2015). The failure nature of sedimentary rocks under different confining pressures becomes complicated due to the effect of BPs. Laboratory tests (Ma et al., 2017, Heng et al., 2019) and field observations (Zou et al., 2017, Lyu et al., 2020) indicated that the bedding direction controls the rock's mechanical properties and significantly influences the hydraulic fracturing behavior and stimulated reservoir volume (SRV). Therefore, rock anisotropy ought to be considered in fracturing projects, otherwise, errors may occur in different magnitudes (Cho et al., 2012). Understanding the anisotropy of mechanical properties and brittleness characteristics of laminated rock is crucial for sweet spot identification and hydraulic stimulation scheme design. 
Brittleness is a significant parameter describing rock failure behavior. Rock brittleness has been widely applied in various rock engineerings, especially wellbore stability analysis and fracability evaluation of hydrocarbon reservoirs (Hucka and Das 1974; Tarasov and Potvin, 2013; Munoz et al. 2016a). In petroleum engineering, rock brittleness plays an essential role in candidate interval selection and hydraulic fracturing design in the hydraulic stimulation of unconventional reservoirs, particularly deep laminated formations. Field experiences show that intervals with higher brittleness are more likely to form complex fracture networks and therefore higher oil/gas production rates (Rickman et al., 2008). Therefore, reasonable and accurate evaluation of brittleness is of great significance for the efficient development of oil/gas reservoirs. Due to the difference of engineering applications and consideration aspects, various definitions of rock brittleness and associated evaluation models have been proposed mainly based on mineral composition (Jarvie et al. 2007, Rybacki et al. 2016), mechanical properties (Hucka and Das 1974, Rickman et al., 2008), stress-strain curves (Chen et al., 2019, Kuang et al., 2021), and energy balance analysis (Kivi et al. 2018). However, there is no universally accepted definition for rock brittleness yet. With the deepening of the understanding of rock brittleness, energy evolution analysis, which can reflect the dynamic process of rock failure, has been widely believed to be more reasonable for brittleness evaluation (Ai et al. 2016, Kivi et al. 2018, Li et al., 2019). Hucka and Das (1974) defined $B I_{l}$ in terms of the elastic energy relative to the total energy absorbed in the pre-peak regime. However, this definition may not be comprehensive enough since it ignores the post-peak characteristics (Kivi et al. 2018). Ai et al. (2016) established index $\mathrm{BI}_{2}$ by integrating the extent of pre-peak plastic energy and post-peak self-sustaining character. However, it failed to consider the effects of strength drop magnitude on brittleness and the influence of plastic deformation on brittleness may not be efficiently formulated. Kivi et al. (2018) suggested $B I_{3}$ as the average of two brittleness indices which described the brittleness of pre-peak and post-peak stages, respectively. Considering the correlation between the pre-peak and post-peak brittleness characteristics, the rationality of averaging the two is questionable. Munoz et al. (2016a) proposed $B I_{4}$ as the ratio of the accumulated elastic energy during the pre-peak stage to the rupture energy. However, it did not consider the pre-peak plastic energy and the residual energy at the post-peak stage. Tarasov and Potvin (2013) redefined $B I_{5}$ as the ratio of the rupture energy to the consumed elastic energy, which did not consider the extent of pre-peak plastic energy. The indices $B I_{1}, B I_{4}$, and $B I_{5}$ suffer the same disadvantages since they fail to fully characterize the effect of energy characteristics of pre- and post-peak stages on brittleness.

Sedimentary rocks can be isotropic or anisotropic depending on the spacing of BPs and the external stress environment. With respect to the mechanical properties, Wasantha et al. (2014) analyzed the effects of BP angle on the mechanical behavior and energy-release characteristics of sandstones. Abbass Tavallali and Andre Vervoort (2010) studied the effect of BP angle on the failure of laminated sandstone using Brazilian tests. Heng et al., 2015 investigated the mechanical properties of shale in the Pengshui area China and considered that the anisotropy of failure mode is closely related to BP angle and confining pressure. Previous studies indicated that the peak strength is the highest at either $\varphi=0^{\circ}$ or $90^{\circ}$ and is the lowest when $\varphi$ varies from $20^{\circ}$ to $40^{\circ}$. The shape of anisotropy curves is mainly U type (Ramamurthy 1993, Nasseriet et al., 2003). Although there are many studies on the anisotropy of rock strength and fracture mode, few studies have focused on the effect of the BP geometry and confining pressure on the mechanical properties and brittleness characteristics of deep laminated sandstones. 
Table 1. Summary of commonly used brittleness indices.

\begin{tabular}{cll}
\hline \multicolumn{1}{c}{ Formulation } & \multicolumn{1}{c}{ Remarks } & \multicolumn{1}{c}{ Reference } \\
\hline$B I_{1}=\frac{d W_{e t}}{d W_{e t}+d W_{p}}$ & $\begin{array}{l}\sigma_{p}=\text { peak strength } \\
\sigma_{r}=\text { residual strength }\end{array}$ & Hucka and Das (1974) \\
$B I_{2}=\frac{d W_{r}+d W_{p}}{d W_{e}+d W_{p}}$ & $\begin{array}{l}\sigma_{c d}=\text { crack damage stress } \\
M=\text { softening modulus } \\
E=\text { elastic modulus }\end{array}$ & Ai et al. (2016) \\
$B I_{3}=\frac{1}{2}\left(\frac{d W_{e}}{d W_{r}}+\frac{d W_{e}}{d W_{e t}+d W_{p}}\right)$ & $\begin{array}{l}D=\text { yield modulus } \\
d W_{r}=\text { rupture energy } \\
d W_{e}=\text { consumed elastic energy }\end{array}$ & Kivi et al. (2018) \\
$B I_{4}=\frac{d W_{e t}}{d W_{r}}$ & $d W_{p}=$ dissipated energy of pre-peak stage & Munoz et al. (2016a) \\
$B I_{5}=\frac{d W_{r}}{d W_{e}}$ & $d W_{e t}=$ total elastic energy & \\
& &
\end{tabular}

Deeply buried sandstone formations (vertical depth is $4200 \sim 6100 \mathrm{~m}$ ), which are rich in oil and gas, are widely distributed in the central Junggar Basin, western China. The tight sandstone reservoirs are characterized by high in-situ stresses, poor reservoir quality, and low production rate, but large exploitation potential. The average porosity of sandstone is $7.69 \%$ and the average permeability is $0.64 \times 10^{-3} \mu \mathrm{m}^{2}$, indicating a low porosity and low permeability reservoir. According to the geological data, core observation, the rock types mainly include siltstone, fine sandstone, argillaceous sandstone, sandy mudstone, and mudstone. The scanning electron microscope (SEM) analysis indicates that pores and cracks of sandstone are well developed, and the main types are primary intergranular pores and dissolution pores. Due to tectonic movement, the geological structure of the sandstone formation is quite complicated, featured by nearly horizontal BPs with various distribution densities. Fig. 1 shows the deep laminated sandstones drilled from different depths. The BPs with different densities can be observed in the sandstone cores. The mechanical properties, failure modes, and brittleness of anisotropic sandstones may be quite complicated. The mechanical and brittle anisotropy of deep laminated sandstones with different confining pressures and BP characteristics should be investigated for accurate prediction of the sweet spot and optimum fracturing scheme design.

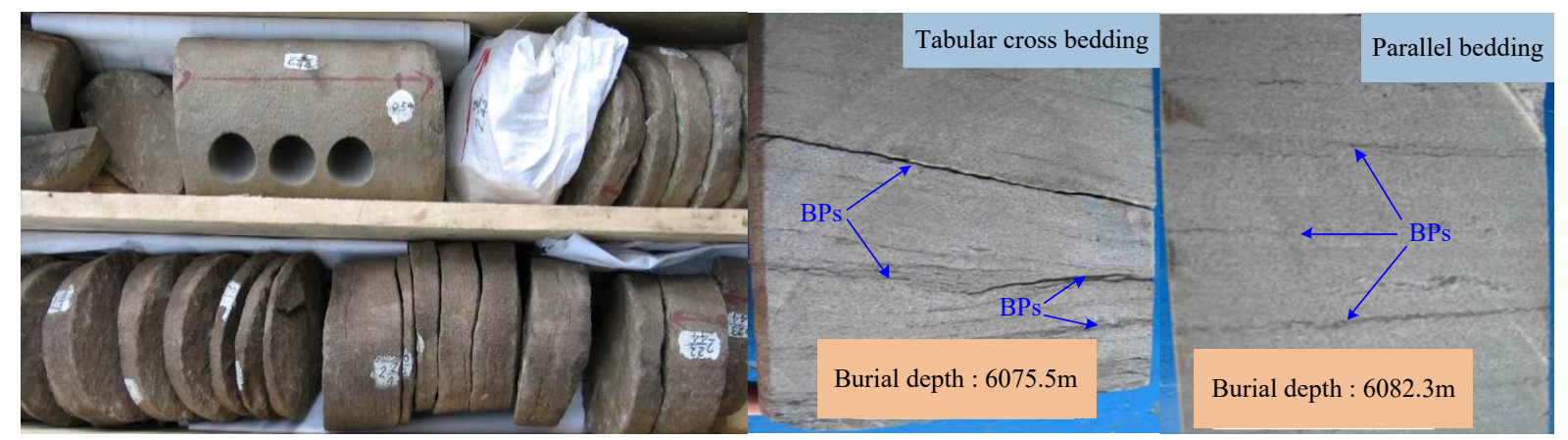

(a)

(b)

Fig. 1. The deep sandstone in the middle Junggar Basin, China: (a) full diameter core, (b) typical sandstone cores with multiple BPs

In this study, an attempt has been made to investigate the anisotropy of mechanical properties and brittleness characteristics of deep laminated sandstones. First, the energy balance and damage evolution process reflected by complete stress-strain curves during the entire process of rock failure was analyzed, based on which 
a novel brittleness index was proposed. Then, the uniaxial and triaxial compression tests on deep sandstones were conducted to validate the accuracy of the new brittleness index. The triaxial compression results of laminated sandstones were employed to examine the ability of the new brittleness index to deal with the relative brittleness degree of sandstones with different confining pressures and BP angles. Furthermore, numerical simulations were performed to further illustrate how BP angle, BP density, and confining pressure control the brittleness anisotropy of deep laminated sandstones using a three-dimensional finite element model. At last, the acoustic emission (AE) characteristics of anisotropic sandstone and correlations between $\mathrm{AE}$ mode and brittleness index were further discussed. The results of this study provided some guidance for brittleness and fracability evaluation and hydraulic fracturing design optimization in deep laminated sandstones.

\section{Evaluation method of sandstone brittleness based on energy evolution}

\subsection{Energy balance and damage evaluation analysis}

Rock damage and failure processes are essentially driven by energy dissipation, transformation, and release, thus accompanied by energy evolution (Ai et al., 2016). The stress-strain curve of rock under loading is the external manifestation of the internal energy state transition (Zhang et al. 2018). It was widely recognized that the whole process of rock rupture is affected by its brittleness. Therefore, the energy evolution characteristics reflected by complete stress-strain curves can be employed to characterize rock brittleness. Xie et al. (2009) pointed that the damage and failure behavior of rock was affected by various processes in which energy is either accumulated or dissipated. Li et al. (2019) suggested that energy accumulation and dissipation behaviors play an essential role in the structural failure of rock, which in turn reflect its brittleness characteristics. Kivi et al. (2018) indicated that the proportion of accumulated elastic energy at pre-peak stage and the rate of release of dissipated energy at post-peak stage were closely related to rock brittleness. The failure of brittle rock can be characterized by a sudden release of elastic energy, accompanied by a rapid increase of dissipated energy at post-peak stage. Furthermore, the damage evolution characteristics driven by energy evolution were also closely affected by rock brittleness. Li et al. (2019) proposed an energy-based damage coefficient $D_{e}$, which was defined as the ratio of the dissipated energy at any time to the total dissipated energy at residual stress, to evaluate the damage evolution characteristic of rock, as shown in Fig. 3. Subsequently, the damage coefficient was used to evaluate rock brittleness. Chen et al. (2019) defined the brittleness index by using the damage evolution rate. Analysis of energy balance and damage evolution process reflected by complete stress-strain curves may contribute to gaining an insight into rock deformation and failure mechanisms and establishing a reasonable brittleness index. 


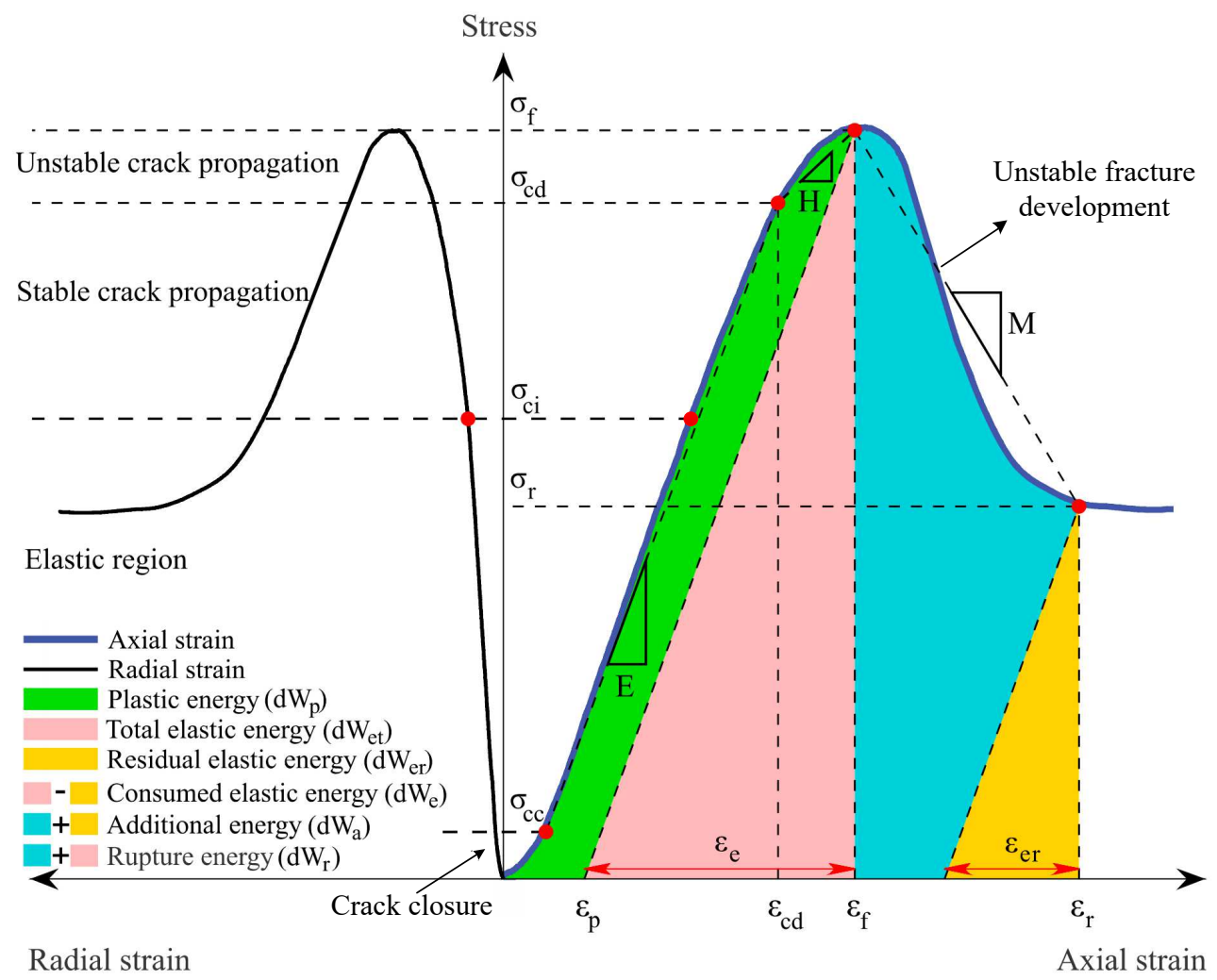

Fig. 2. Typical stress-strain curve and associated characteristic stresses and strains and strain energy for brittle rocks (According to Kivi et al. (2018)).

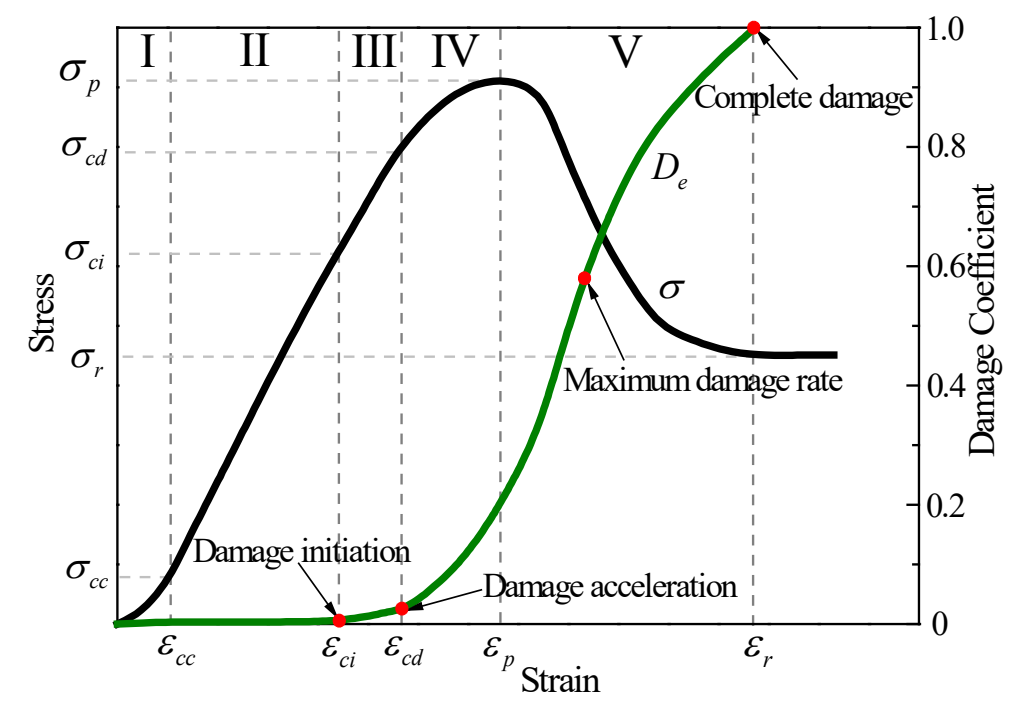

Fig. 3. Energy damage evolution over the whole process of rock failure (According to Li et al. (2019)).

The whole rupture process of rock specimens under loading can be divided into five stages (Figs. 2 and 3).

(I). Crack closure $\left(0-\sigma_{c c}\right)$. At this stage, partial energy absorbed from outside is transformed into dissipated energy due to the closure of microcracks and pores, which leads to a concave-upward stress-strain response. This stage is terminated at crack closure stress and is followed by linear elastic deformation. There is almost no damage at this stage $\left(D_{e}=0\right)$.

(II). Elastic region $\left(\sigma_{c c}-\sigma_{c i}\right)$. At this stage, the rock specimen undergoes elastic deformation and the elastic energy accumulates continuously. Due to the linear elastic deformation, no damage occurs at this stage $\left(D_{e}=0\right)$. This stage is terminated at crack initiation stress and is followed by non-linear plastic deformation. 
(III). Stable crack propagation $\left(\sigma_{c i}-\sigma_{c d}\right)$. This stage involves cracks initiation and stable propagation, accompanied by energy dissipation, resulting in irretrievable damage and plastic deformation. The damage of rock initiates and increases slowly. Meanwhile, the elastic energy continues to accumulate and the dissipated energy begins to increase gradually with the extension of cracks.

(IV). Unstable crack propagation $\left(\sigma_{c d}-\sigma_{p}\right)$. This stage involves cracks unstable propagation and extensive coalescence. When the stress reaches the crack damage stress, the plastic deformation of the rock specimen intensifies and the damage accelerates. With the increase of loading, the elastic energy and dissipated energy increase continuously. When the axial stress reaches peak strength, the elastic energy reaches its maximum value, which is determined by the elastic energy storage capacity of a rock. For brittle rocks, more elastic energy is stored within the specimen and less energy is dissipated at this stage, therefore, little damage occurs at the pre-peak stage. Rock brittleness is weakened by the dissipated energy at the pre-peak stage.

(V). Unstable fracture development $\left(\sigma_{f}-\sigma_{r}\right)$. At this stage, the structural failure of rock specimen occurs, driven by the combining effect of released elastic energy and extra energy (the area of the blue region in Fig. 2) applied by external loads. This process is accompanied by a remarkable increase in dissipated energy. The damage accumulates rapidly until the rock specimen is completely failed $\left(D_{e}=1\right)$. This stage is terminated at residual stress. Partial elastic energy is unconsumed and stored within the specimen, which is denoted by residual elastic energy. For absolute brittle rocks, the rupture process occurs in a self-sustained manner by solely consuming the stored elastic energy at the pre-peak stage, and no extra energy is required. In this case, the damage coefficient $D_{e}$ increases sharply after the axial stress reaches peak strength. Brittle rocks release more elastic energy and consume less extra energy to sustain failure, while ductile rocks need more extra energy to rupture the specimen.

\subsection{A novel energy-based brittleness index}

From the above analysis, it can be seen that the levels of strain energies corresponding to characteristic stresses and strains are the essential factors determining rock brittleness. The definition of the brittleness index must take the energy characteristics at both pre-peak and post-peak stages of the complete stress-strain curve into account. Ai et al. 2016 suggested the mechanical properties of either the pre-peak or the post-peak stage should not be considered separately, but instead be regarded as a whole failure process. From the perspective of energy balance, the more elastic energy accumulated and less dissipated energy produced at the pre-peak stage, and the more elastic energy consumed and the less extra energy required at the post-peak stage, the more brittle the rock specimen will be. Therefore, the rock brittleness is redefined as the integrated capability of storing much elastic energy at the pre-peak stage and self-sustaining complete failure at the post-peak stage. The higher brittleness involves: (a) rock has more elastic energy storage capacity and less dissipated energy, and little damage occurs at the pre-peak stage; (b) rock rupture is more relied on the released elastic energy, instead of extra energy; (c) the elastic energy is released more rapidly and completely, and damage evolves rapidly at the post-peak stage. Accordingly, the new brittleness index $B I$ is defined as follows based on energy balance.

$$
\begin{gathered}
B I=B I_{1} \times B I_{2} \\
B I_{1}=\frac{d W_{e t}}{d W_{p}+d W_{r}} \\
B I_{2}=\frac{d W_{e t}-d W_{e r}}{d W_{r}}
\end{gathered}
$$


Where $d W_{e t}$ and $d W_{p}$ are the accumulated elastic energy and the dissipated energy at the pre-peak stage, respectively; $d W_{r}$ and $d W_{e r}$ are the rupture energy and residual elastic energy at the post-peak stage, respectively.

Defined as the ratio of the stored elastic energy during the pre-peak stage to the total dissipated or consumed energy from loading to rupture, the brittleness index $B I_{1}$ quantitatively evaluates the elastic energy storage capacity of a rock. Defined as the ratio of the consumed elastic energy to the rupture energy during the post-peak stage, the brittleness index $B I_{2}$ represents the extent to which the rupture process occurs in a self-sustaining manner. For absolute brittle rock, the absorbed energy is all transformed into elastic energy at the pre-peak stage, the stored elastic energy during pre-peak stage is completely released to drive the rupture of rock and no additional energy is needed to maintain the failure at the post-peak stage, leading to $B I_{1}=B I_{2}=1$. For absolute ductile rock, the absorbed energy is all transformed into dissipated energy at the pre-peak stage, the rupture energy is nearly infinite and the residual elastic energy equals accumulated elastic energy at the pre-peak stage, resulting in $B I_{1}=B I_{2}=0$. Both $B I_{1}$ and $B I_{2}$ indicate an increasing trend of brittleness from 0 to 1 . Considering the correlations between pre-peak and post-peak failure behavior of rock, a multiplication of $B I_{1}$ and $B I_{2}$ is adopted to comprehensively characterize its brittleness characteristics.

As shown in Fig. 2, the energy parameters are represented by the area enclosed by the stress-strain curve and stress/strain axis, which considers the comprehensive information reflected by the stress-strain curves and thus ensuring an accurate brittleness index. The energy parameters in Eqs. (2) and (3) can be calculated from the complete stress-strain curves directly:

$$
\begin{gathered}
d W_{e t}=\frac{1}{2 E} \sigma_{f}^{2} \\
d W_{e r}=\frac{1}{2 E} \sigma_{r}^{2} \\
d W_{p}=d W_{t}-d W_{e t}=\int_{0}^{\varepsilon_{f}} \sigma d \varepsilon-\frac{1}{2 E} \sigma_{f}^{2} \\
d W_{r}=d W_{e t}+d W_{a}-d W_{e r}=\frac{1}{2 E}\left(\sigma_{f}^{2}-\sigma_{r}^{2}\right)+\int_{\varepsilon_{f}}^{\varepsilon_{r}} \sigma d \varepsilon
\end{gathered}
$$

Where $\sigma_{f}$ and $\varepsilon_{f}$ are the peak stress and peak strain, respectively. $\sigma_{r}$ and $\varepsilon_{r}$ are the residual stress and residual strain, respectively. $E$ is the Elastic modulus.

The brittleness index $B I$ possesses sufficient physical meaning and is capable of quantifying the whole range from ductility to brittleness on a continuous and monotonic scale from 0 to 1 . The definition of $B I$ regards the pre-peak and post-peak stages as a whole process by integrating $B I_{1}$ and $B I_{2}$, which comprehensively consider the energy characteristic of pre-peak and post-peak stages. Since the effect of confining pressure and BP geometry on rock mechanical behavior is directly reflected by the stress-strain curves, $B I$ is also able to characterize the effect of BP and confining pressure on rock brittleness. Moreover, it can describe the plastic yield level and elastic energy storage capacity at pre-peak stage, in addition to the extent and rate of strength degradation and damage evolution rate at post-peak stage. 


\subsection{Experimental validation}

\subsubsection{Triaxial compression test}

To verify the validity of $B I$ in reflecting the restraining effect of confining pressures on rock brittleness, a series of compression tests on deep sandstone specimens were performed on a triaxial test system GCTS RTR-1500, as illustrated in Fig. 4. Several components of the GCTS RTR-1500 triaxial test system are as follows: a uniaxial loading system, a radially deformed sensor, a digital acoustic analysis system, a confining pressure system, a pore pressure system, and a computer system. A set of sandstone cores were drilled from the deep sandstone reservoir with a depth of $6071.3 \sim 6087.4 \mathrm{~m}$ in the central Junggar Basin, western China. Since the cementation strength of BPs in deep laminated sandstones was relatively low, it was hard to obtain sandstones with different BP angles from full-diameter cores. Therefore, the isotropic sandstones without BPs were processed into cylinder specimens (diameter $\times$ height $=25 \mathrm{~mm} \times 50 \mathrm{~mm}$ ), and their failure behaviors under triaxial compressions were tested in the laboratory.

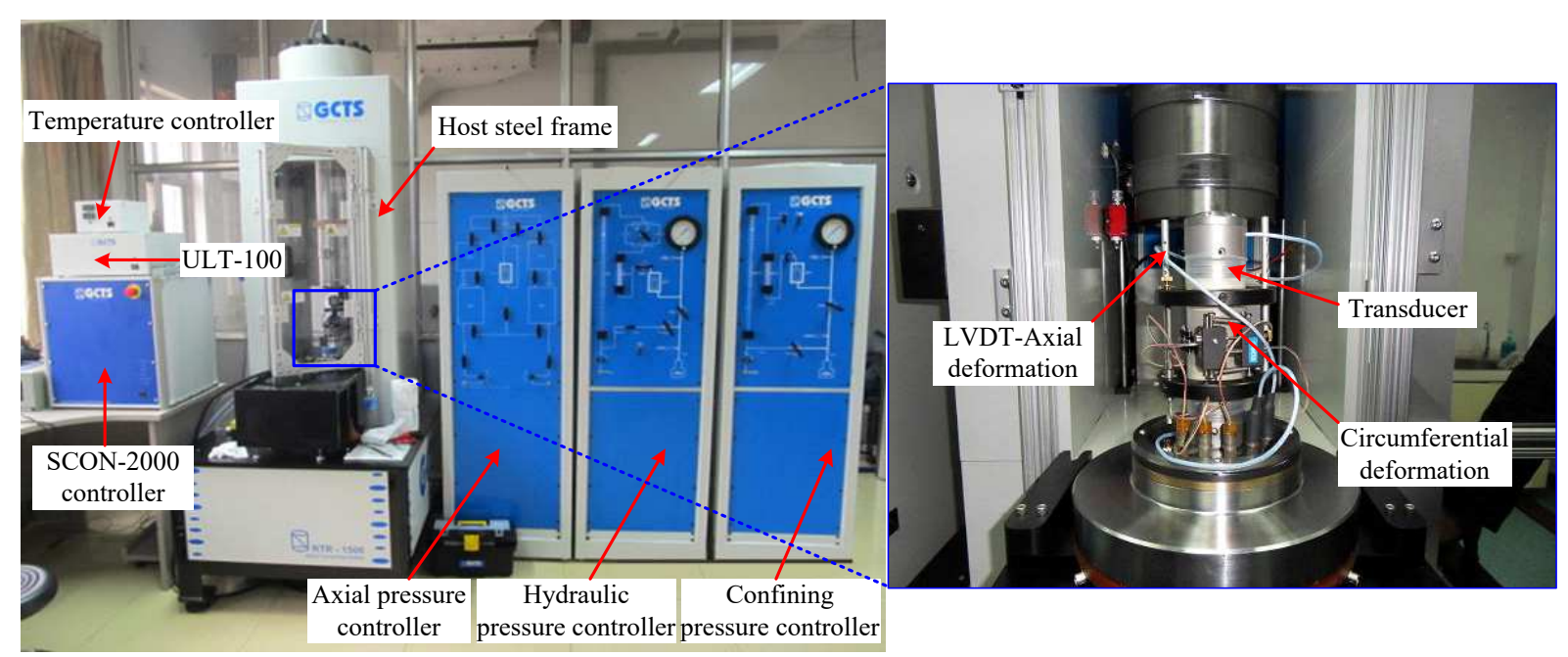

Fig. 4. The GCTS RTR-1500 triaxial test system

The confining pressures were set at $0 \mathrm{MPa}, 30 \mathrm{MPa}, 40 \mathrm{MPa}$, and $60 \mathrm{MPa}$. The test process was controlled by uniaxial deformation with a loading rate of $2 \times 10^{-6} \mathrm{~m} / \mathrm{s}$ until rock failure. The test operation flow follows the method suggested by the International Society for Rock Mechanics (ISRM 2007). Fig. 5 illustrates the stress-strain curves and failure planes of sandstones. The mechanical parameters are listed in Table 2. 


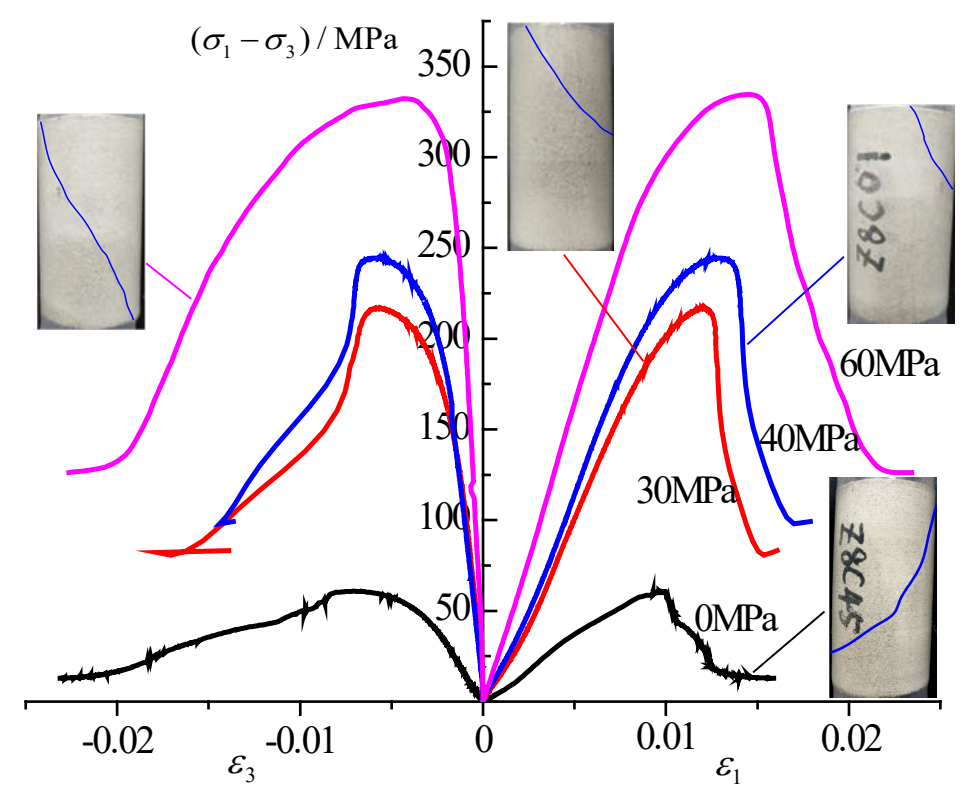

Fig. 5. Stress-strain curves of deep sandstone specimens under different confining pressures

To verify the capability of $B I$ in distinguishing the relative degree of the brittleness of anisotropic sandstone, the experimental results of deep laminated sandstones under uniaxial and triaxial compressions were also analyzed (Deng et al. 2018). The BP angle is defined as the angle between the BP and the axis of the cylindrical specimen, represented as $\beta$. The sandstone specimens with five sets of BP angle are drilled, at $\beta=0^{\circ}, 30^{\circ}, 45^{\circ}$, $60^{\circ}$, and $90^{\circ}$. The stress-strain curves of laminated sandstone specimens are shown in Fig. 6 . The mechanical parameters are listed in Table 2.
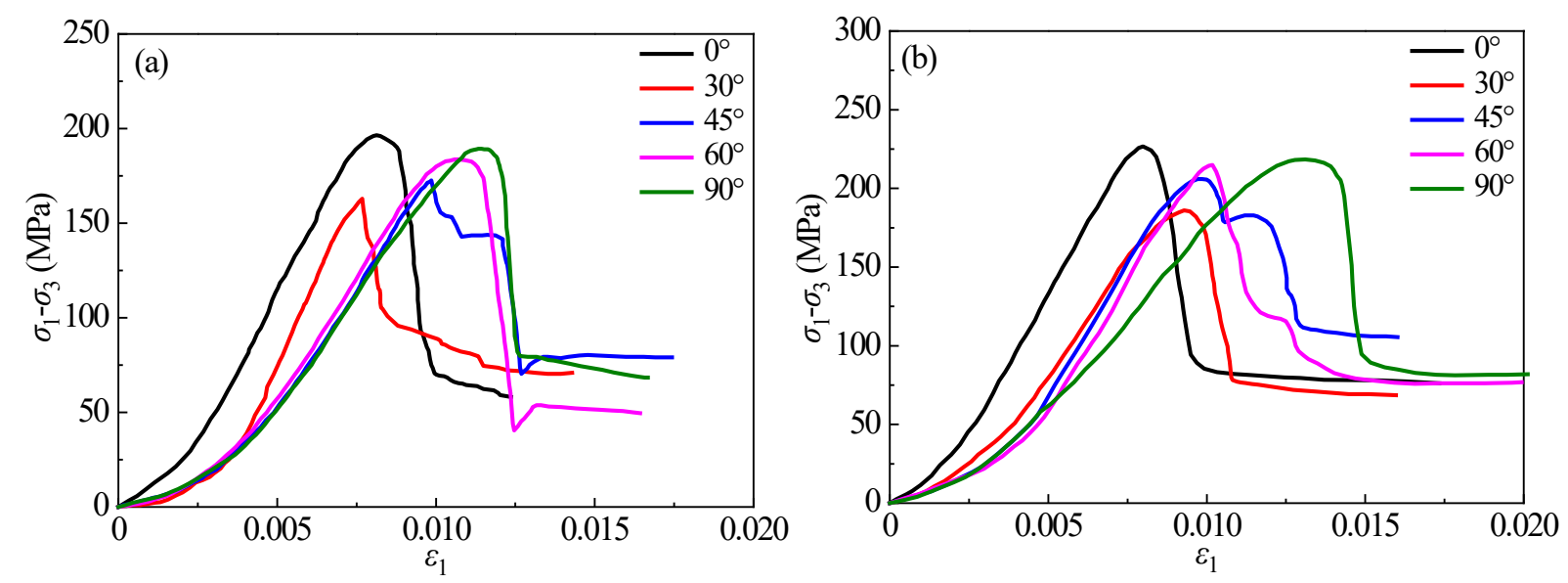

Fig. 6. Stress-strain curves of laminated sandstone specimens under uniaxial and triaxial compressions: (a) $\sigma_{3}=10 \mathrm{MPa}$, (b) $\sigma_{3}=15 \mathrm{MPa}$ (Deng et al. (2018).

Table 2. Mechanical parameters of sandstone specimens

\begin{tabular}{ccccccccc}
\hline Rock type & $\begin{array}{c}\sigma_{3}(\mathrm{MPa}) \\
/ \beta\left(^{\circ}\right)\end{array}$ & $\sigma_{p}(\mathrm{MPa})$ & $\varepsilon_{p}(\%)$ & $\sigma_{r}(\mathrm{MPa})$ & $\varepsilon_{r}(\%)$ & $E(\mathrm{GPa})$ & $v$ & $B I$ \\
\hline Deep & 0 & 60.3 & 0.99 & 17.8 & 1.27 & 7.1 & 0.281 & 0.452 \\
isotropic & 30 & 216.7 & 1.21 & 82.7 & 1.50 & 23.7 & 0.161 & 0.363 \\
sandstone & 40 & 244.1 & 1.31 & 101.6 & 1.66 & 26.0 & 0.197 & 0.275 \\
& 60 & 334.4 & 1.47 & 127.9 & 2.18 & 33.3 & 0.213 & 0.168 \\
\hline Deep & $0^{\circ}$ & 196.5 & 1.15 & 81.9 & 1.26 & 34.3 & $/$ & 0.562 \\
laminated & $30^{\circ}$ & 162.9 & 1.08 & 52.9 & 1.24 & 33.6 & $/$ & 0.382
\end{tabular}




\begin{tabular}{ccccccccc} 
sandstone & $45^{\circ}$ & 172.6 & 0.99 & 79.7 & 1.26 & 31.9 & $/$ & 0.227 \\
$(10 \mathrm{MPa})$ & $60^{\circ}$ & 184.5 & 0.77 & 88.4 & 0.83 & 30.4 & $/$ & 0.389 \\
& $90^{\circ}$ & 190 & 0.81 & 92.6 & 1.01 & 28.9 & $/$ & 0.422 \\
\hline & $0^{\circ}$ & 226.7 & 0.79 & 85.5 & 0.99 & 36.3 & $/$ & 0.459 \\
Laminated & $30^{\circ}$ & 185.9 & 0.93 & 78.3 & 1.08 & 35.1 & $/$ & 0.361 \\
sandstone & $45^{\circ}$ & 205.9 & 0.98 & 111.5 & 1.30 & 34.0 & $/$ & 0.201 \\
$(15 \mathrm{MPa})$ & $60^{\circ}$ & 214.8 & 1.01 & 82.5 & 1.40 & 31.9 & $/$ & 0.273 \\
& $90^{\circ}$ & 218.4 & 1.31 & 89.3 & 1.52 & 29.2 & $/$ & 0.395 \\
\hline
\end{tabular}

\subsubsection{Brittleness evaluation with $B I$}

To verify the capability of the new brittleness index to deal with the effect of confining pressure and anisotropy on rock brittleness, the experimental results of uniaxial and triaxial compressions were used to calculate the brittleness indices. For deep isotropic sandstones, the effect of confining pressure on brittleness index $B I$ was investigated. The variations of brittleness indices with respect to confining pressure were plotted in Fig. 7. The brittleness indices of sandstone showed a negative correlation with the confinement levels, which was inconsistent with the results of (Tarasov and Potvin, 2003). The value of $B I$ decreased from 0.452 to 0.168 when the confining pressure increased from 0 to $60 \mathrm{MPa}$. With the increase of confining pressure, the brittleness index of deep sandstone decreased rapidly. Considering the energy transformation characteristics at pre-peak and post-peak stages, the brittleness indices $B I_{1}, B I_{2}$, and $B I$ showed similar trends with elevated confining pressure. As the confining pressure increases, sandstone's ability to store elastic energy at pre-peak stage and consume elastic energy at post-peak stage decreases, which results in lower brittleness. Li et al., (2019) indicated that the confining pressure mainly affected the proportion of stored elastic energy at pre-peak stage and the dissipation extent of accumulated elastic energy at post-peak stage.

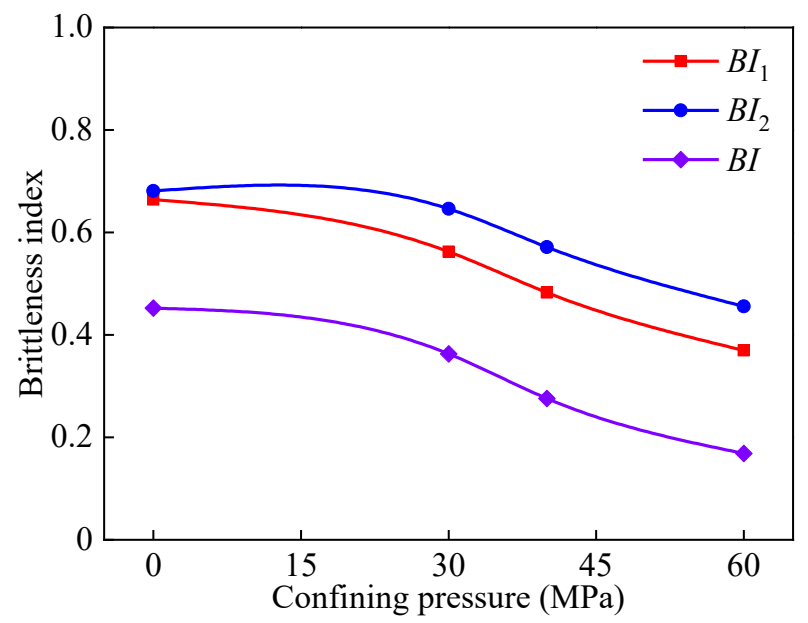

Fig. 7. Brittleness indices of deep isotropic sandstone under different confining pressures

For deep laminated sandstones, the effect of BP angle on mechanical properties and brittleness index $B I$ was investigated. Fig. 8 demonstrated the peak strength, elastic modulus, and brittleness index of deep laminated sandstone under different BP angles. The mechanical properties and brittleness of sandstone are significantly affected by confining pressure and BP angle. As shown in Fig. 8a, the elastic modulus and peak strength of sandstone increased with the increase of confining pressure. With the increase of BP angle, the elastic modulus of sandstone decreased, while the peak strength first decreased and then increased. The peak strength reached its minimum value at BP angle $=30^{\circ}$. The brittleness index of sandstone decreased with the increase of confining pressure, which agreed well with the conclusion drawn from the deep isotropic sandstones. The brittleness index of sandstone decreased when BP angle increased from $0^{\circ}$ to $45^{\circ}$, 
then increased when BP angle increased from $45^{\circ}$ to $90^{\circ}$, showing a U-shaped variation of high value on both sides and low value in the middle.
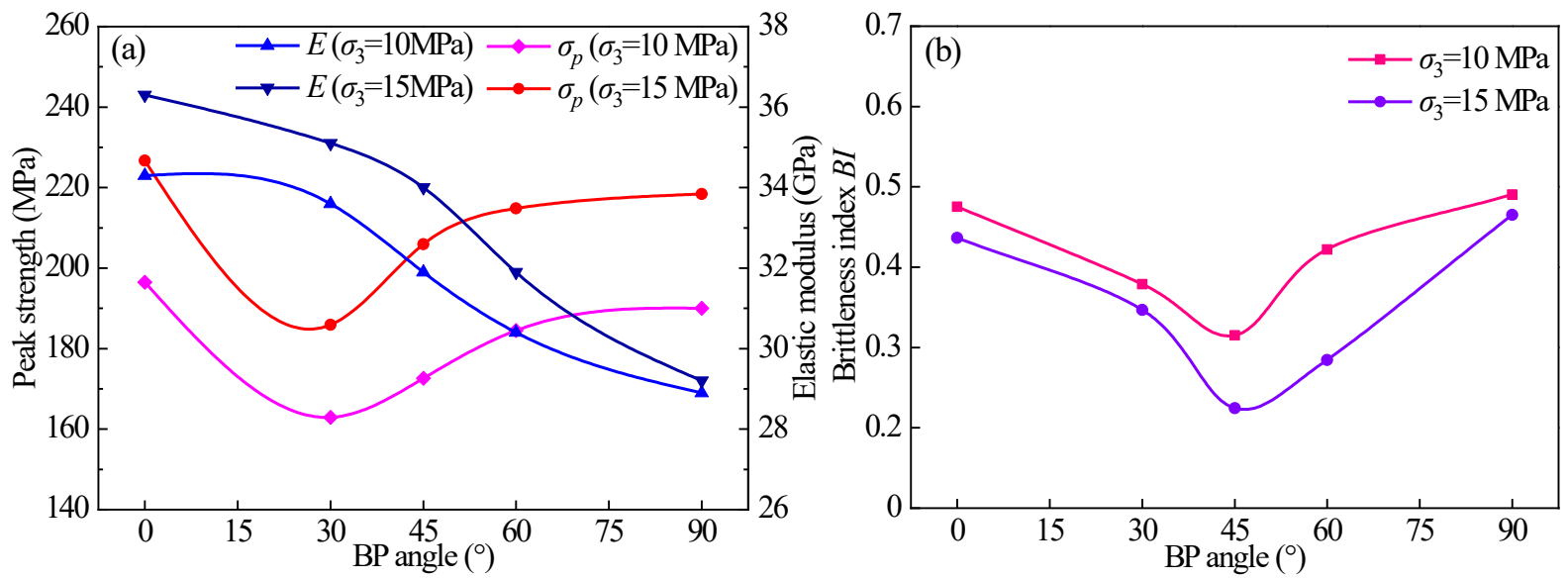

Fig. 8. (a) Peak strength, elastic modulus, and (b) brittleness index of deep laminated sandstone under different BP angles.

\subsubsection{Comparison of $B I$ with other brittleness indices}

Energy-based brittleness indices are widely believed considered to be able to reasonably reflect the dynamic process of rock rupture and can more precisely for brittleness evaluation (Ai et al. 2016, Kivi et al. 2018). Therefore, some commonly used energy-based brittleness indices, as listed in Table 1, were employed to compare with the new index $B I$. To directly compare the relative degree of brittleness evaluated by different indices, positive correlation indices (brittleness index is positively related to rock brittleness, see $B I, B I_{1}, B I_{3}$, and $B I_{4}$ ) and negative correlation indices (brittleness index is negatively related to rock brittleness, see $B I_{2}$ and $B I_{5}$ ) are normalized by $\left(B I-B I_{\min }\right) /\left(B I_{\max }-B I_{\min }\right)$ and $\left(B I-B I_{\max }\right) /\left(B I_{\min }-B I_{\max }\right)$, respectively. The variation of normalized brittleness indices under different confining pressures was plotted in Fig. 9. As illustrated in Fig. 9, the overall downward trend of six brittleness indices curves reflects that the brittleness of sandstone decreases with the increase of confining pressure. The calculation results of six brittleness indices characterized well the brittleness variation of sandstone under elevated confining pressure. As can be seen from Fig. 9, BI lies in the middle of these six brittleness indices when confining pressure is $30 \mathrm{MPa}$ and $40 \mathrm{MPa}$, indicating that $B I$ can not only effectively deal with the inhibition effect of confining pressure on rock brittleness, but also reasonably reflect the variation degree of sandstone brittleness with the change of confining pressure. The relative degree of sandstone brittleness under different confining pressures calculated by $B I$ is close to those calculated by $B I_{3}$ and $B I_{4}$, which further proves the accuracy of $B I$.

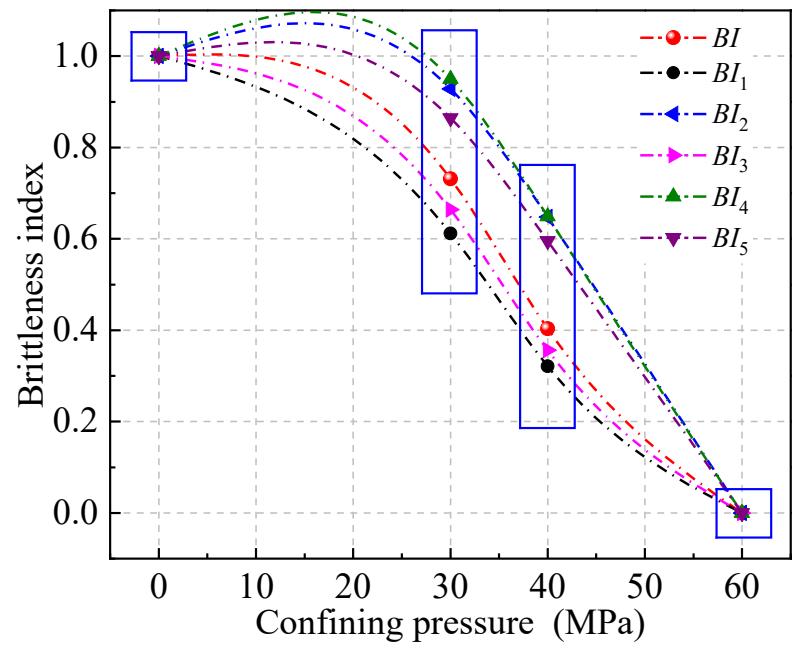

Fig. 9. Normalized brittleness indices of sandstone specimens under triaxial compressions 
The variations of normalized brittleness indices under different BP angles were illustrated in Fig. 10. As shown in Fig. 10, the variation tendency of sandstone brittleness determined by $B I, B I_{2}, B I_{3}, B I_{4}$, and $B I_{5}$ was quite similar. With the increasing BP angle, the sandstone brittleness first decreased and then increased, and the sandstone specimen possessed the lowest brittleness with a BP angle of $45^{\circ}$. However, $B I_{1}$ failed to characterize the brittleness variation of sandstone specimens under the BP angle of $0^{\circ}$ to $90^{\circ} . B I_{1}$ was defined as the ratio of elastic energy and total absorbed energy during the pre-peak stage. It failed to consider the post-peak stage as it thoroughly ignored this process (Li et al., 2019). Although the variation trend of $B I_{4}$ is consistent with other indices, the relative brittleness degree of sandstone specimens with different BP angles reflected by $B I_{4}$ is different from other indices. $B I_{4}$ was defined as the ratio of stored elastic energy during pre-peak stage and rupture energy without considering the dissipated energy at pre-peak stage and residual elastic energy at post-peak stage, which may lead to an incomplete description of the energy evolution process. Fully considered the energy evolution characteristics at both pre-peak and post-peak stages, $B I_{2}, B I_{3}$, and $B I_{5}$ reflected well the variation of the brittleness of sandstone specimen under different BP angles, which was in good consistency with the new brittleness index $B I$. As shown in Fig. 10, BI lies in the middle of these six brittleness indices when BP angles vary from $0^{\circ}$ to $90^{\circ}$, indicating that $B I$ can precisely characterize the relative degree of sandstone brittleness with different BP angles. Thus, BI can more accurately represent the sandstone brittleness under different confining pressure and is more sensitive to changes in brittleness induced by anisotropy.
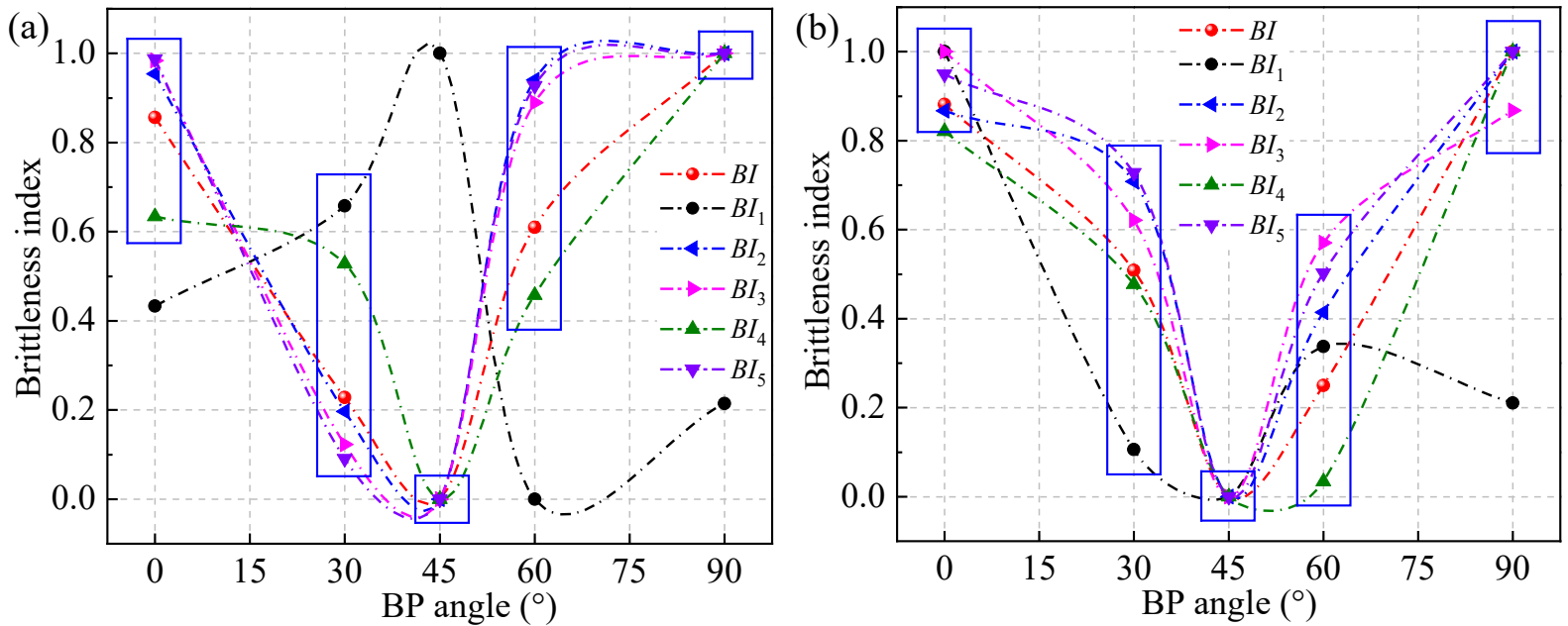

Fig. 10. Normalized brittleness indices of anisotropic sandstone specimens under triaxial compressions: (a) confining pressure is $10 \mathrm{MPa}$, (b) confining pressure is $15 \mathrm{MPa}$.

\section{Numerical simulation}

\subsection{A brief introduction of the numerical model RFPA3D}

The RFPA3D is a three-dimensional FEM-based model designed to simulate the entire failure process of rock materials (Tang et al., 1998, Li et al., 2012). The model is developed based on the idea that heterogeneity leads to non-linearity and causes progressive failure behavior of rock. The macroscopic nonlinear deformation characteristics of rock are reflected by the weakening of mechanical properties caused by the accumulation of microcracks in the damage process of heterogeneous meso-elements. By introducing heterogeneity of rock properties into the model, RFPA3D can simulate the non-linear deformability of a quasi-brittle behavior with an ideal brittle constitutive law. The AE account is reflected by the cumulative number of damaged meso-elements and the elastic energy released by the damaged meso-elements is used to reflect the amount of AE energy during the failure process of rock material.

The mechanical properties of representative volume elements (REV) are randomly distributed to reflect the initial random distributed weakness at the mesoscopic scale. An eight-node element was employed as the 
fundamental element. The mechanical parameters of elements (such as Young's modulus and strength properties) are assumed to follow a Weibull distribution:

$$
f(u)=\frac{m}{u_{0}}\left(\frac{u}{u_{0}}\right)^{m-1} \exp \left(-\frac{u}{u_{0}}\right)^{m}
$$

where $u$ is the mechanical parameters of rock obtained from laboratory tests; $u_{0}$ is the mean value of the variable $u$; and $m$ is the degree of homogeneity, which is called the homogeneity index. A larger $m$ indicates a more homogeneous material and vice versa. $f(u)$ is the distribution density of the variable $u$.

Based on Lemaitre's hypothesis of strain equivalence (Lemaitre, 1971), the rock damage progress can be regarded as the degradation of the elastic modulus. As the damage evolves, the elastic modulus of the element gradually decreases, as defined below:

$$
E=(1-D) E_{0}
$$

where $D$ is the damage variable; $E_{0}$ and $E$ are elastic modulus of the undamaged and damaged elements, respectively.

In RFPA3D, the state of elements can be classified by damage variable into three kinds that are elastic elements $(D=0)$, damaged elements $(0<D<1)$, and full failure elements $(D=1)$. They are distinguished by different colors as shown in Fig. 11.

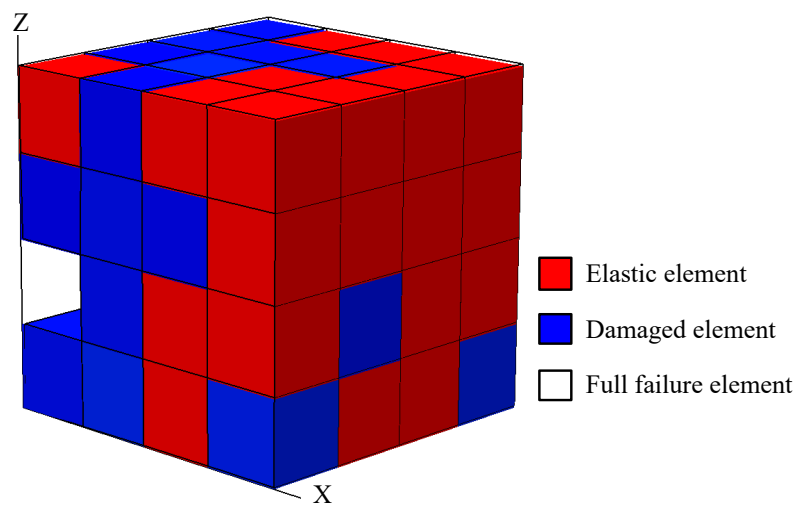

Fig. 11. Schematic diagram of the elastic elements, damaged elements and full failure elements in RFPA3D.

The damage evolution process of RVE under compression and tension is shown in Fig. 12.

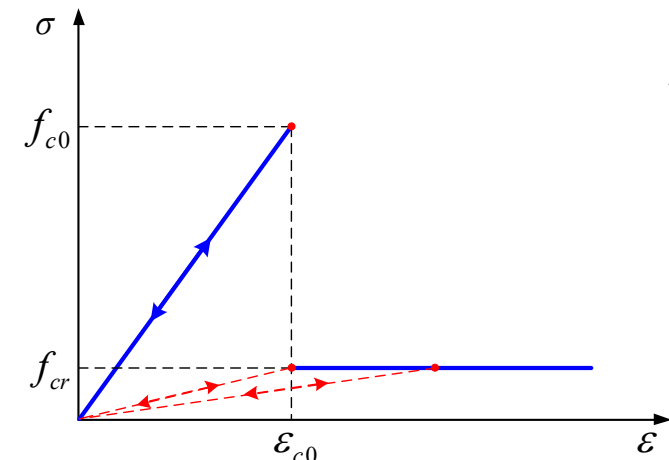

(a)

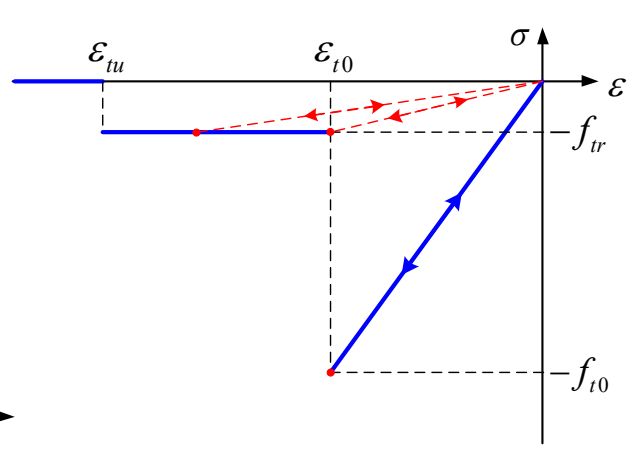

(b)

Fig. 12. Elastic-brittle damage constitutive law of elements subject to uniaxial stress: (a) under uniaxial tensile stress; (b) under uniaxial compressive stress.

When the tensile stress in the element reaches its tensile strength, $\sigma_{3} \leq-f_{t 0}$, the variable $D$ of the element under uniaxial tension can be expressed as: 


$$
D= \begin{cases}0 & \varepsilon>\varepsilon_{t 0} \\ 1-\frac{\lambda \varepsilon_{t 0}}{\varepsilon} & \varepsilon_{t u} \leq \varepsilon \leq \varepsilon_{t 0} \\ 1 & \varepsilon \leq \varepsilon_{t u}\end{cases}
$$

where $\varepsilon_{t 0}$ is the tensile strain at the elastic limit, as shown in Fig. 3a. $\varepsilon_{t u}$ is the ultimate tensile strain, which is defined as $\varepsilon_{t u}=\eta \varepsilon_{t 0} . \eta$ is the ultimate strain coefficient. $\lambda$ is the residual tensile strength coefficient.

When the equivalent principal tensile strain $\bar{\varepsilon}$ reaches the threshold strain, $\varepsilon_{t 0}$, under multiaxial stress states, the element is assumed to be damaged in the tensile mode. $\bar{\varepsilon}$ is defined as follows:

$$
\bar{\varepsilon}=-\sqrt{\left\langle-\varepsilon_{1}\right\rangle^{2}+\left\langle-\varepsilon_{2}\right\rangle^{2}\left\langle-\varepsilon_{3}\right\rangle^{2}}
$$

where $\varepsilon_{1}, \varepsilon_{2}$, and $\varepsilon_{3}$ are the three principal strains. $<>$ is a function defined as $<x>=\left\{\begin{array}{ll}x & x \geq 0 \\ 0 & x<0\end{array}\right.$.

Then, the variable $D$ is expressed as:

$$
D= \begin{cases}0 & \bar{\varepsilon}>\varepsilon_{t 0} \\ 1-\frac{\lambda \varepsilon_{t 0}}{\bar{\varepsilon}} & \varepsilon_{t u} \leq \bar{\varepsilon} \leq \varepsilon_{t 0} \\ 1 & \bar{\varepsilon} \leq \varepsilon_{t u}\end{cases}
$$

When the element is under uniaxial compression, the constitutive law is shown in Fig. 12b. The Mohr-Coulomb criterion is selected as damage threshold to describe the element damage under a compressive or shear stress condition:

$$
\sigma_{1}-\sigma_{3} \frac{1+\sin \varphi}{1-\cos \varphi} \geq f_{c 0}
$$

where $\sigma_{1}$ and $\sigma_{3}$ are the principal stresses. $\varphi$ is the internal friction angle. $f_{c 0}$ is the uniaxial compressive strength. The variable $D$ under uniaxial compression can be expressed as:

$$
D= \begin{cases}0 & \varepsilon<\varepsilon_{c 0} \\ 1-\frac{\lambda \varepsilon_{c 0}}{\varepsilon} & \varepsilon \geq \varepsilon_{c 0}\end{cases}
$$

where $\varepsilon_{c 0}$ is the compressive strain at the elastic limit.

When the Mohr-Coulomb criterion is satisfied for the strength of the element subjected to multi-axial stress, the maximum compressive principal strain $\varepsilon_{c 0}$ can be obtained as follows:

$$
\left.\varepsilon_{c 0}=\frac{1}{E}\left[f_{c 0}+\frac{1+\sin \varphi}{1-\sin \varphi} \sigma_{3}-\mu\left(\sigma_{1}+\sigma_{2}\right)\right]\right]
$$

where $\mu$ is Poisson's ratio. Thus, the shear damage under triaxial stress conditions can be extended from Eq. (16) as follows:

$$
D= \begin{cases}0 & \varepsilon_{1}<\varepsilon_{c 0} \\ 1-\frac{\lambda \varepsilon_{c 0}}{\varepsilon_{1}} & \varepsilon_{1} \geq \varepsilon_{c 0}\end{cases}
$$

The Young's modulus of the damaged element under distinct stress levels can then be obtained as per the previously derived equations related to the damage variable $D$. 


\subsection{Mechanical parameters calibration}

For RFPA3D, the mesoscopic mechanical parameters must be calibrated before input into the numerical model. Therefore, the experimental results of deep sandstone specimens under the uniaxial compression test were used to calibrate the meso-mechanical parameters. A cylinder numerical model (diameter $\times$ height $=25 \mathrm{~mm} \times 50$ $\mathrm{mm}$, the same size as the physical sandstone specimen) was designed for the uniaxial compression test. The numerical specimen was meshed into 502,400 finite elements. The numerical test was controlled by uniaxial deformation with a top uniaxial displacement loading rate of $0.002 \mathrm{~mm} / \mathrm{step}$ until specimen failure.

Fig. 7(a-b) shows the physical and numerical specimens before and after failure. Fig. 7(c) shows the comparison between experimental and numerical stress-strain curves. It can be seen that the numerically simulated stress-strain curve and failure mode of the sandstone specimen are in good agreement with the experimental results. The calibrated meso-mechanical parameters of the sandstone matrix were obtained, as listed in Table 1. As a kind of natural discontinuity, BPs have relatively smaller strength and elastic modulus than sandstone matrix. Table 1 has also given the physical and mechanical parameters of BPs, which were referred to as the experimental results of Li et al. 2017 and Heng et al. 2020.

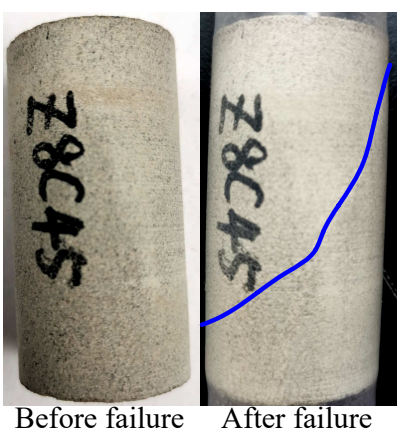

(a)

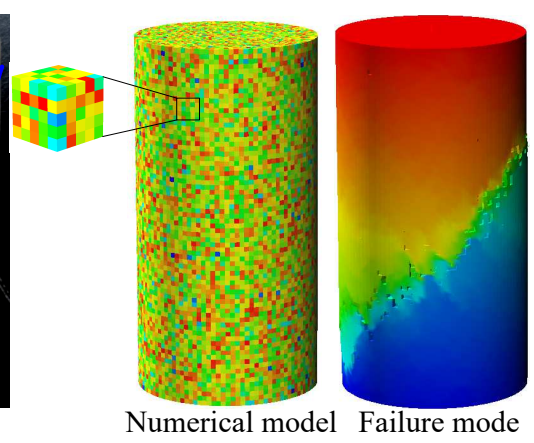

(b)

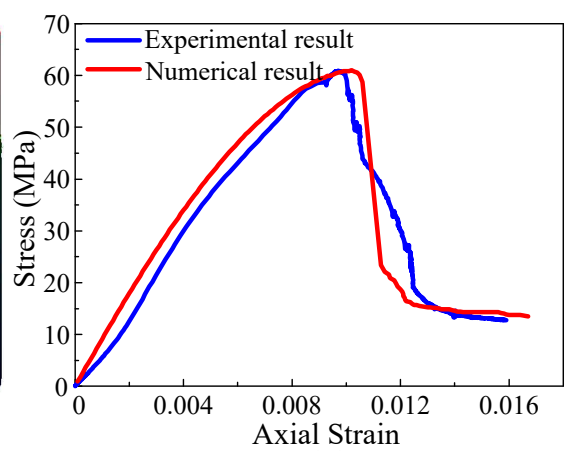

(c)

Fig. 13. A numerical simulation model of hydraulic fracturing

Table 2. Physical and mechanical parameters of sandstone matrix and BPs.

\begin{tabular}{ccccc}
\hline Parameter & Symbol & Unite & Sandstone matrix & BP \\
\hline Elastic modulus & $E$ & GPa & 11 & 5 \\
Uniaxial compressive strength & $U C S$ & MPa & 250 & 25 \\
Homogeneity index & $m$ & - & 1.85 & 1.85 \\
Ratio of compression-tensile strength & $r$ & - & 10 & 15 \\
Friction angle & $\varphi$ & $\circ$ & 35 & 20 \\
Poisson ratio & $v$ & 1 & 0.22 & 0.25 \\
Residual strength coefficient & $\lambda$ & - & 0.1 & 0.1 \\
Ultimate tensile strain coefficient & $\eta_{t}$ & - & 5 & 5 \\
Ultimate compressive strain coefficient & $\eta_{c}$ & - & 100 & 100 \\
\hline
\end{tabular}

\subsection{Model validation}

Five numerical models with different brittle mineral contents were established to validate the ability of RFPA3D to simulate the rock failure process and distinguish the brittle and ductile behavior of rock under compression. It is assumed that the sandstone sample consists only of brittle minerals and ductile minerals. The contents of brittle minerals were set to be $100 \%, 80 \%, 50 \%, 20 \%$, and $0 \%$, respectively. For simplicity, all brittle (or ductile) minerals are given the same set of mechanical parameters. The model details, such as size, meshes, and loading conditions, were the same as the previously established one, as shown in Fig. 13(b). According to 
the unique behaviors of brittle minerals and ductile minerals (Zhang et al., 2016), the mechanical parameters given in Table 3 are employed in this model.

Table 3. Physical-mechanical parameters of brittle and ductile minerals.

\begin{tabular}{ccccc}
\hline Parameter & Symbol & Unite & Brittle mineral & Ductile mineral \\
\hline Elastic modulus & $E$ & $\mathrm{GPa}$ & 45 & 11 \\
Uniaxial compressive strength & $U C S$ & $\mathrm{MPa}$ & 250 & 250 \\
Homogeneity index & $m$ & - & 1.85 & 1.85 \\
Ratio of compression-tensile strength & $r$ & - & 20 & 10 \\
Friction angle & $\varphi$ & $\circ$ & 38 & 30 \\
Poisson ratio & $v$ & 1 & 0.11 & 0.28 \\
Residual strength coefficient & $\lambda$ & - & 0.02 & 0.3 \\
Ultimate tensile strain coefficient & $\eta_{t}$ & - & 5 & 5 \\
Ultimate compressive strain coefficient & $\eta_{c}$ & - & 100 & 100 \\
\hline
\end{tabular}

The evolution of damage fields (five figures on the left) of the ductile and brittle specimen and their elastic modulus map (the figure on the right) after failure are presented in Fig. 14. The two specimens undergo a progressive failure under loading. Some element failures initially appear, then they joint to form a fracture and finally the fracture coalescence causes the specimen failure. However, obvious difference lies between the two specimens. The ductile specimen ruptures with a shear fracture penetrating the entire rock body, while multiple failure planes appear on the brittleness specimen. Under the same compression conditions, the complete failure of the brittle specimen occurs at a time step of 19 , while the ductile specimen fully fails at a time step of 155 . The ductile specimen has a larger peak strain than the brittle specimen, which is consistent with the experimental results. Generally, compared with ductile specimens, brittle specimens are more prone to rupture rapidly with multiple failure surfaces under loading.

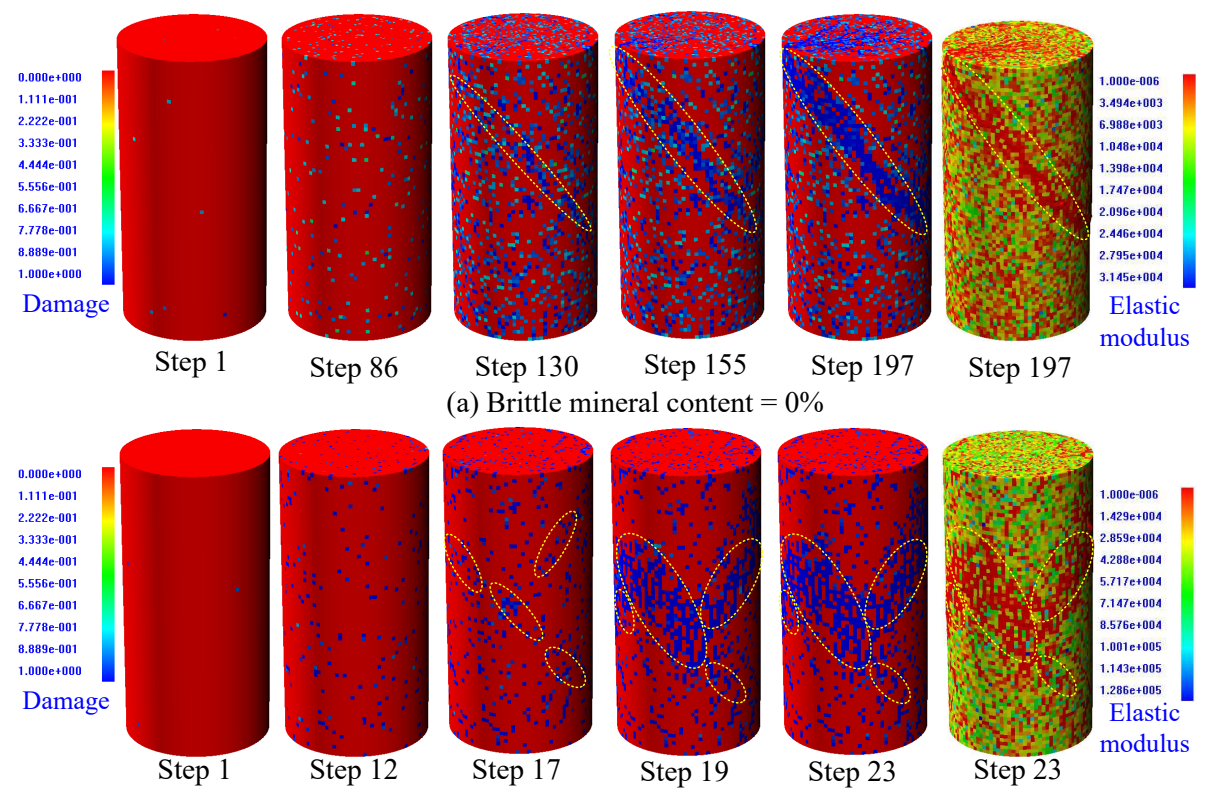

(b) Brittle mineral content $=100 \%$

Fig. 14. The evolution of damage fields of the ductile and brittle specimens and their elastic modulus map The stress-strain curves of rock specimens with different brittle mineral contents are illustrated in Fig. 15. It can be seen that with the decrease of brittle mineral content, the elastic modulus of the specimen decreases, the peak strain and residual strength increase, and the stress-strain curve presents obvious plastic characteristics. The brittleness of each specimen has been evaluated based on the new brittleness index $B I$, which is also shown in 
Fig. 15. With the decrease of brittle mineral content, the $B I$ decreases, indicating the decrease of brittleness and the increase of ductility. The above conclusions are consistent with the theoretical analysis (Zhang et al., 2019, Ai et al. 2016) and experimental results (Tarasov and Potvin, 2013) with respect to rock brittleness evaluation, which demonstrates the ability of RFPA3D to simulate the brittle or ductile behaviors of rock specimen.

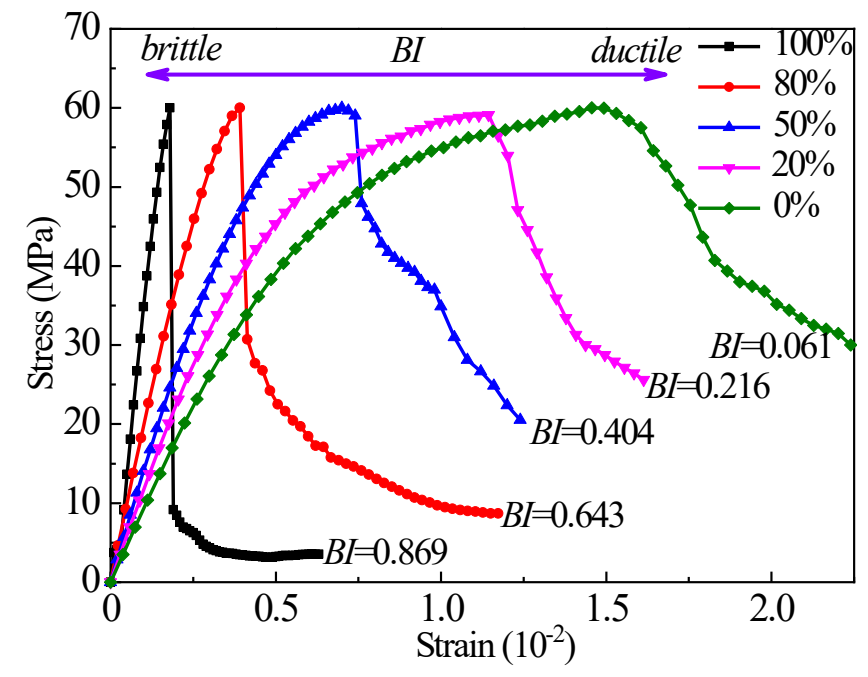

Fig. 15. Numerically simulated stress-strain curves of rock specimens with different brittle mineral contents and their corresponding $B I$ s.

\section{Results and analysis}

\subsection{Anisotropy of mechanical property, brittleness and failure mode}

The BP angle has a significant impact on the mechanical behavior and brittleness characteristics of sandstone (Wasantha et al., 2014, Chang et al., 2015). In this section, the effects of BP angle on the mechanical properties and brittleness index of laminated sandstone under uniaxial compression are investigated. Five numerical models with $\varphi=0^{\circ}, 30^{\circ}, 45^{\circ}, 60^{\circ}$, and $90^{\circ}$, respectively, are established, as shown in Fig. 16(a). The uniaxial compression numerical tests are conducted based on the RFPA3D model. The model details, such as size, meshes, and loading conditions, were the same as the previously established one, as shown in Fig. 13(b). The BPs with a density of $160 \mathrm{~m}^{-2}$ are uniformly distributed on the sandstone specimens.

The bedding effect of laminated sandstone is remarkable. The BP angle is an important factor affecting the failure mode of sandstone. The comparisons of failure modes between numerical specimens and physical specimens are illustrated in Figs. 16(b)-(c). The failure modes of the numerical specimens with different BP angle are quite similar to the experimental results of (Khanlari et al., 2015), which further prove the accuracy of the model. Four failure modes of laminated sandstones under uniaxial compression can be observed, which are as follows:

(a) $\varphi=0^{\circ}$. Multiple cracks propagate along the axial direction, which is the tensile splitting parallel to the BPs. The multiple fracture surfaces divide the specimen into a plurality of thin plate-like rock blocks that still have bearing capacity. In the process of continuous loading, the rock block is compressed and bent until part of the rock block is buckled and broken. The sandstone matrix undergoes shear failure under axial stress.

(b) $\varphi=30^{\circ}, 45^{\circ}$ and $60^{\circ}$, the specimen forms one or more shear slip failure surfaces along the BPs. The ruptured rock specimen forms a flat fracture surface running through the whole specimen along the BPs, and obvious shear slip along BPs occurs. 
(c) $\varphi=90^{\circ}$, multiple cracks propagate in the matrix and along the BPs, presenting a composite failure mode. The rock specimen forms a vertical fracture surface dominated by tensile failure and a horizontal fracture surface dominated by shear failure.

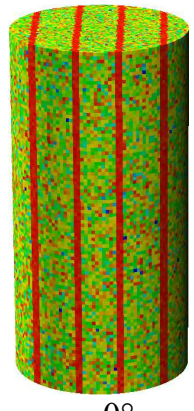

$\varphi=0^{\circ}$
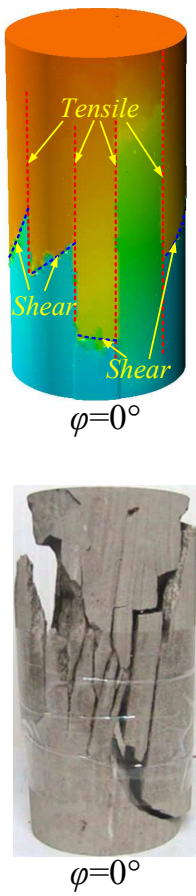

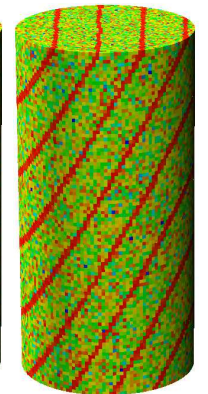

$\varphi=30^{\circ}$

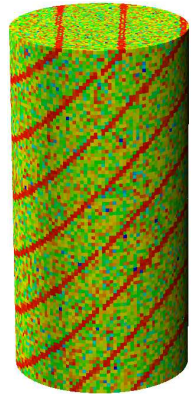

$\varphi=45^{\circ}$

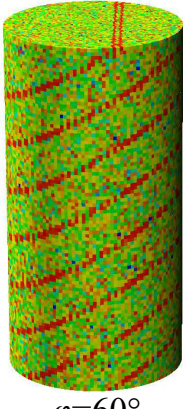

$\varphi=60^{\circ}$

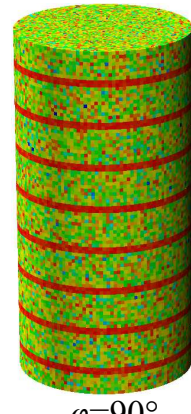

$\varphi=90^{\circ}$

(a) Numercial model
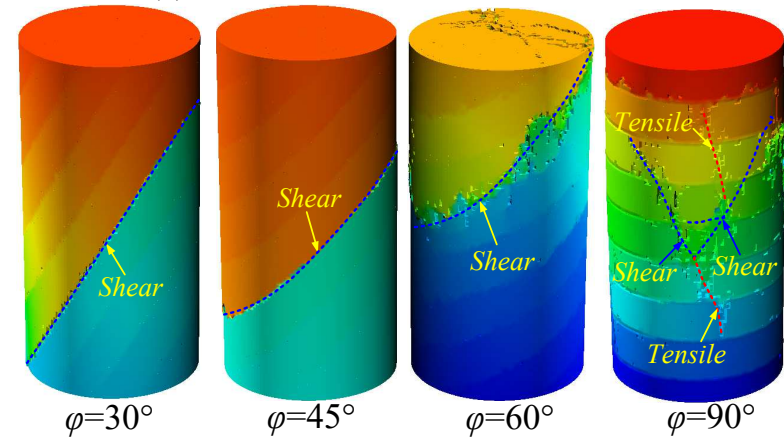

(b) Failure mode
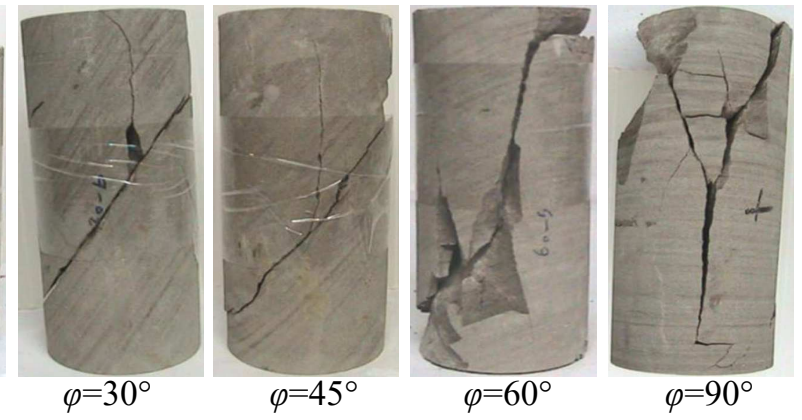

(c) Physical specimen

Fig. 16. (a) Numerical specimens with different BP angles and comparison of failure modes between (b) numerical specimens and (c) physical specimens (Khanlari et al., 2015)

The mechanical properties and brittleness index of numerical specimens with different BP angles are calculated from the stress-strain curves (shown in Fig. 19b) and plotted in Fig. 17. As shown in Fig. 17a, with the increase of BP angle, the elastic modulus of sandstone decreased, while the peak strength decreased first and then increased. The peak strength reached its minimum value at $\mathrm{BP}$ angle $=30^{\circ}$. The brittleness index of sandstone decreased when BP angle increased from $0^{\circ}$ to $45^{\circ}$, then increased when BP angle increased from $45^{\circ}$ to $90^{\circ}$, showing a U-shaped variation of high value on both sides and low value in the middle. The variation trend of elastic modulus, peak strength, and $B I$ with BP angle is consistent with the experimental results (shown in Fig. 8), which further verifies the validity of the numerical model. From Fig. 17, it can be concluded that the mechanical properties (especially the peak strength) of laminated sandstone are closely related to the angle between the direction of principal stress and BPs. When the BP angle is $30^{\circ}$, the sandstone is prone to shear slip failure along the BPs and possesses the lowest peak strength. Bedding structure is the weak plane in the formation, which is the source of anisotropy of mechanical properties, brittleness characteristics, and failure mode of sandstones. Shear slip failure along the BPs is one of the main reasons for wellbore instability in 
sandstone formations. In the process of drilling horizontal wells, the mechanical strength of wellbore rock in vertical and horizontal sections is high and thus the stability is good, while wellbore instability is most likely to occur in the deflection-making stage. Additionally, in the process of sandstone rupture, when the principal stress is perpendicular or parallel to BPs, it may present higher brittleness and more prone to generate multiple fracture surfaces due to brittle failure.
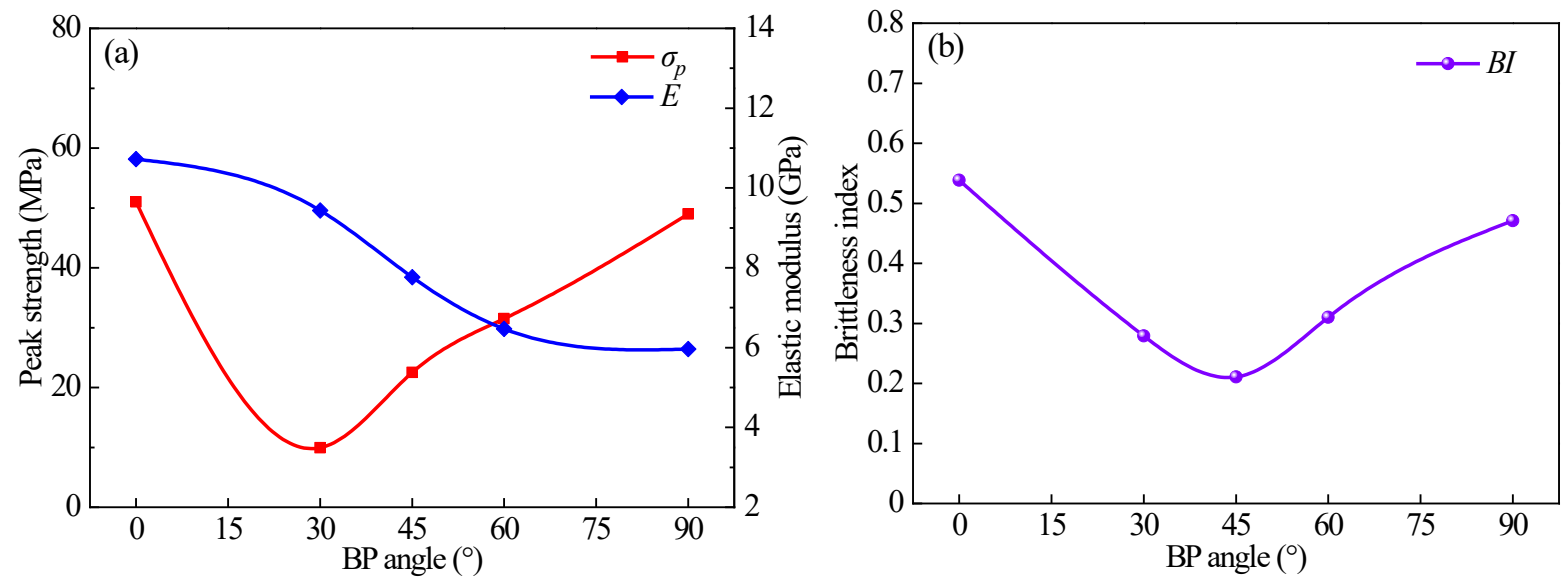

Fig. 17. (a) Peak strength, elastic modulus, and (b) brittleness index of sandstone specimens under different BP angles

\subsection{Effects of BP density}

The development of the bedding structure may affect the mechanical anisotropy of sandstone. The BP density is an important index reflecting the development of bedding structures. The Formation MicroScanner (FMS) well logs and core observation results indicated that the BP density varied significantly with burial depth in deep laminated sandstones of the central Junggar Basin, western China. The BP density is defined as the number of BPs per unit length and denoted by BPD, $\mathrm{m}^{-1}$. In this section, the effects of BP density on the anisotropy of mechanical properties and brittleness of sandstone under uniaxial compressions are investigated. A series of numerical cases with different BP densities and BP angles are discussed. The numerical specimens are illustrated in Fig. 18. The above simulation results of specimens with a BP density of $160 \mathrm{~m}^{-1}$ are used for comparison. Fig. 19 illustrates the stress-strain curves of sandstone specimens with different BP densities and BP angles. 

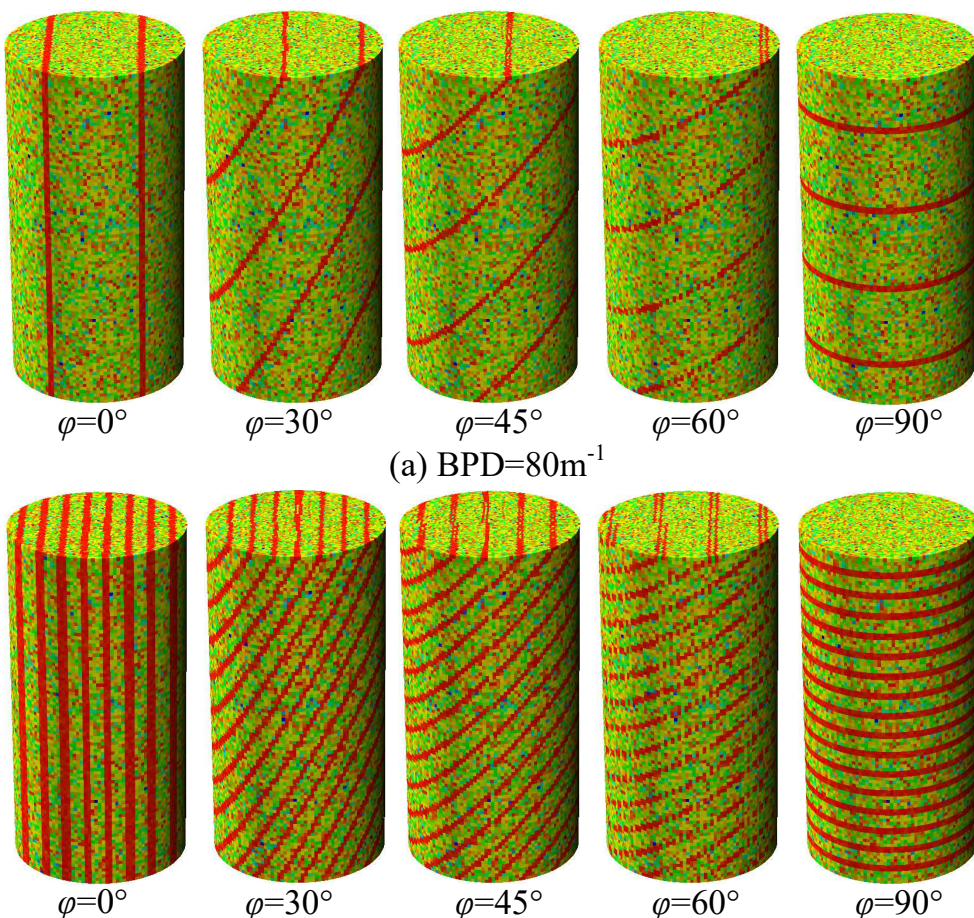

(a) $\mathrm{BPD}=80 \mathrm{~m}^{-1}$
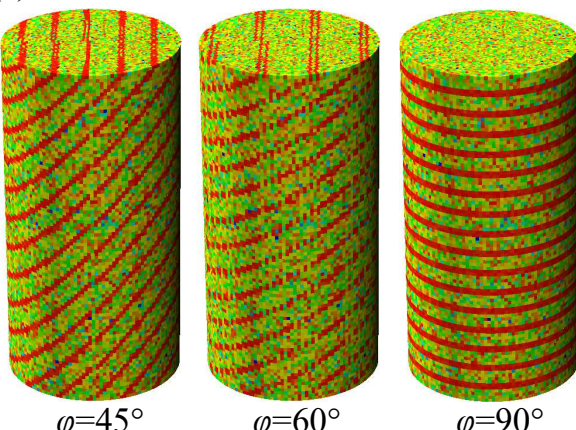

(b) $\mathrm{BPD}=320 \mathrm{~m}^{-1}$
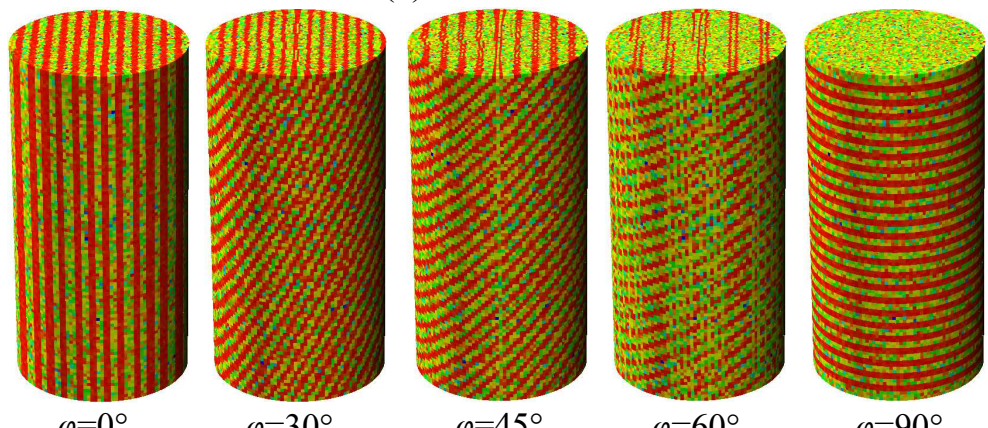

(c) $\mathrm{BPD}=480 \mathrm{~m}^{-1}$

$\varphi=90^{\circ}$

Fig. 18. The numerical models of laminated sandstone specimens with different BP densities and BP angles
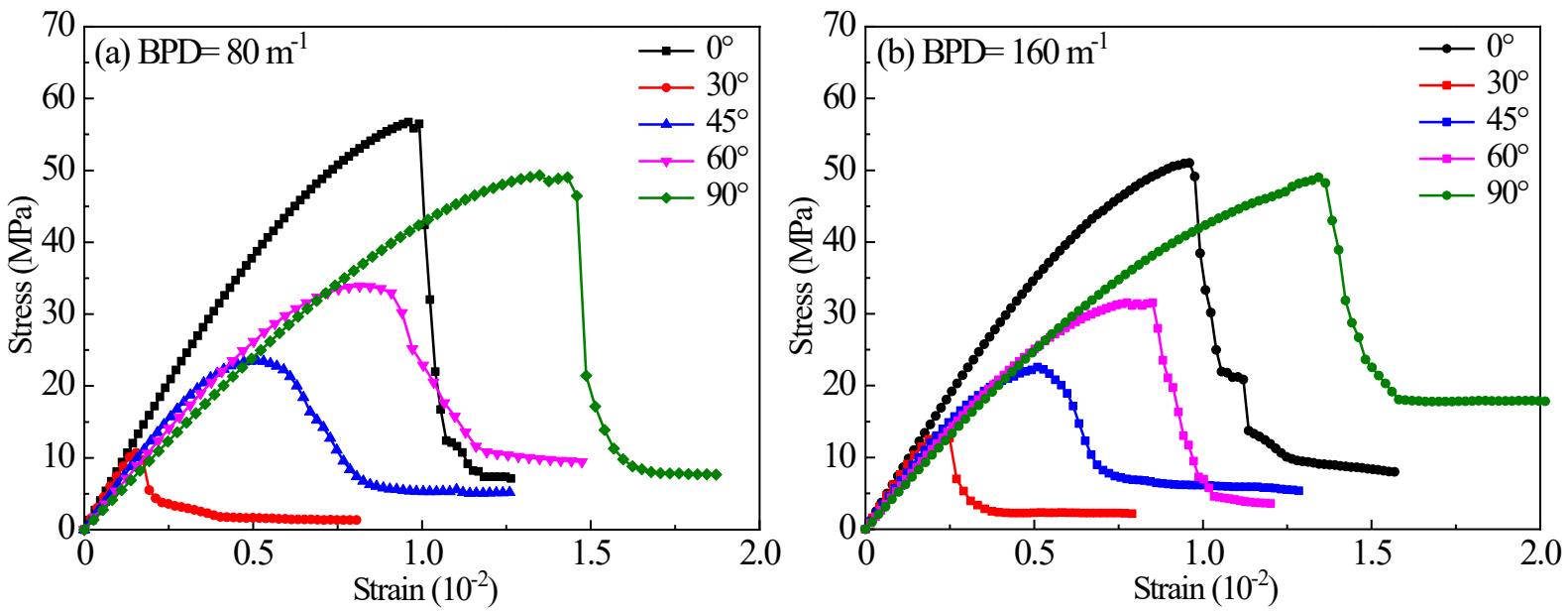

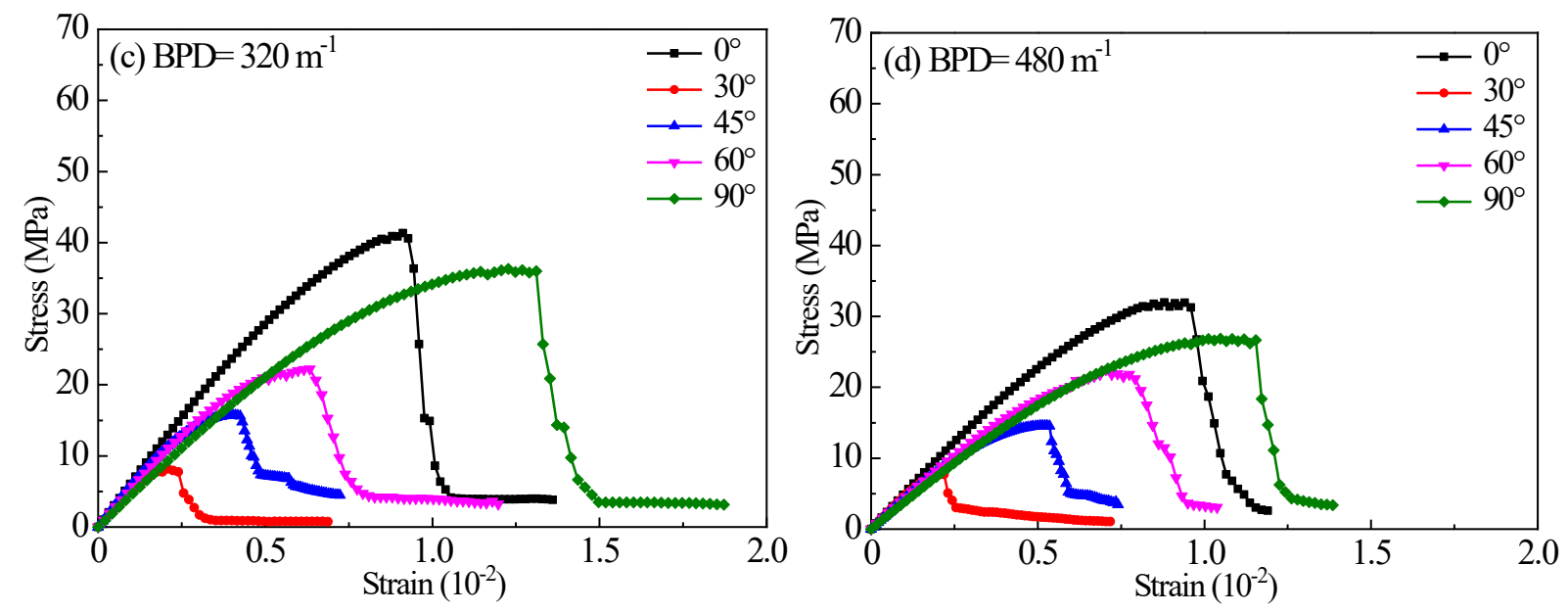

Fig. 19. The stress-strain curves of sandstone specimens with different BP densities and BP angles

The mechanical properties and brittleness index of sandstone specimens with different BP densities were obtained from the stress-strain curves and plotted in Fig. 20. The BP density has a significant effect on the mechanical properties and brittleness characteristics of laminated sandstones. As shown in Fig. 20a, the peak strength decreases with the increase of BP density, which is consistent with the experimental results of Longmaxi shale (Wang et al., 2017). This conclusion explains the reason for the difference in compressive strength of laminated sandstones from the perspective of the distribution of BP density. The tension or shear failure is more likely to occur on sandstones with large BP densities, and the peak strength of sandstone is controlled by BP density. Moreover, the peak strength of sandstone with a BP angle of $0^{\circ}$ and $90^{\circ}$ decreases most significantly, while that of sandstone with a BP angle of $30^{\circ}$ decreases the least. From Fig. 20b, there is a negative correlation between BP density and elastic modulus of sandstone. With the increase of BP angle, the variation range of elastic modulus becomes smaller. Fig. 20c shows the variation of brittleness index BI with BP density and BP angle. It is obvious that BP density significantly affects the brittleness anisotropy. With the increase of BP density, the rock heterogeneity decreases and its mechanical heterogeneity weakens. Therefore, the brittleness anisotropy decreases with the increase of BP density.
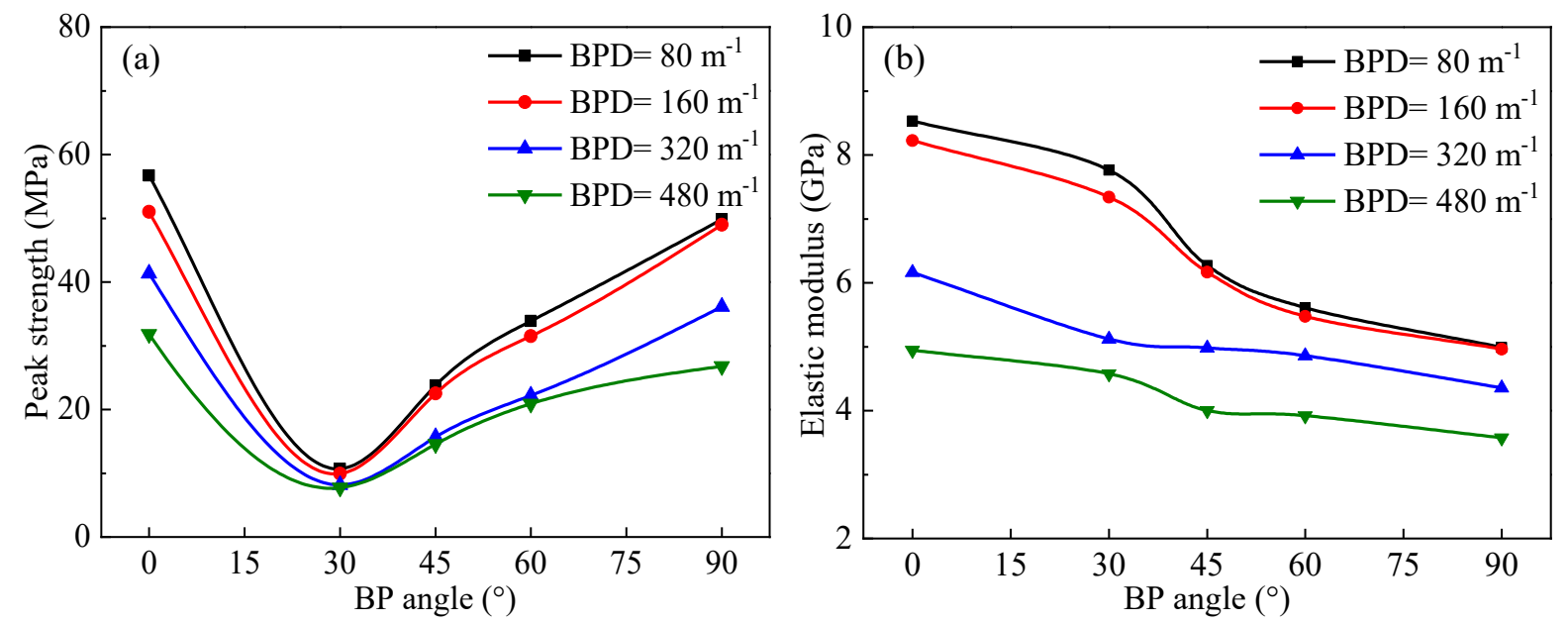

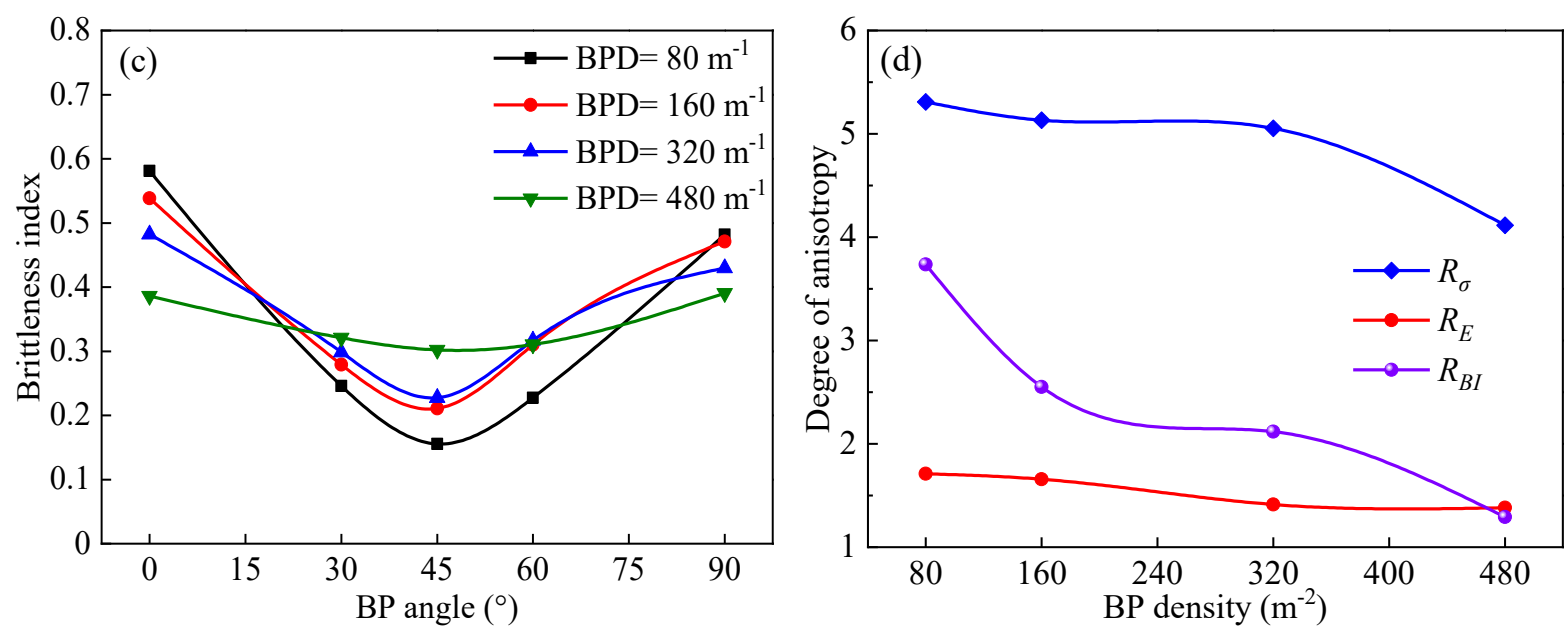

Fig. 20. (a) Peak strength, (b) elastic modulus, and (c) brittleness index of sandstone specimens under different BP densities and BP angles

To quantify the anisotropic characteristics of sandstone's mechanical properties, the anisotropic degrees of peak strength, elastic modulus, and brittleness index are defined as follows, respectively (Niandou et al., 1997):

$$
\begin{gathered}
R_{\sigma}=\frac{\sigma_{p \max }}{\sigma_{p \min }} \\
R_{E}=\frac{E_{\text {max }}}{E_{\text {min }}} \\
R_{B I}=\frac{B I_{\text {max }}}{B I_{\text {min }}}
\end{gathered}
$$

Where $\sigma_{p \max }$ and $\sigma_{p \min }$ are the maximum and minimum peak strength, respectively. $E_{\max }$ and $E_{\min }$ are the maximum and minimum elastic modulus, respectively. $B I_{\max }$ and $B I_{\min }$ are the maximum and minimum brittleness index, respectively.

Fig. 20d illustrated the effect of BP density on the degree of anisotropy of deep laminated sandstone. With the increase of BP density, the anisotropic degrees of peak strength, elastic modulus, and brittleness decrease. The anisotropic degree of peak strength ranges from 4.11 to 5.31, indicating a strong anisotropic formation. The BP density has the most significant effect on $R_{B I}$ among the three parameters, followed by $R_{B I}$, and $R_{E}$ has the smallest variation range with BP density.

\subsection{Effects of confining pressure}

Due to the existence of BPs, the peak strength, elastic modulus, and brittleness of sandstone present significant anisotropic characteristics. The mechanical anisotropy is mainly controlled by BP angle, BP density, and confining pressure. Analyzing the anisotropic characteristics of sandstone under different conditions is beneficial to better understand the failure mechanism of sandstone with weak BPs, and provide guidance for fracability evaluation and optimum design of hydraulic fracturing. Extensive studies have investigated the confining pressure effect on the mechanical properties of anisotropic rocks (Jin et al., 2020). However, there was still a lack of qualitative analysis on the effect of confining pressure on the brittleness anisotropy of deep laminated sandstones. The confining pressure changes the anisotropic characteristics of mechanical properties, thus influencing the stress-strain response and brittleness anisotropy of sandstone. In this section, the effects of confining pressure on the anisotropy of mechanical properties and brittleness of sandstone are numerically investigated. The numerical specimens with a BP density of $160 \mathrm{~m}^{-2}$ (Fig. 16a) are used for numerical simulations 
and their stress-strain response and brittleness characteristics under different confining pressures are tested. Fig. 21 illustrates the stress-strain curves of sandstone specimens with different confining pressures and BP angles. It can be seen that with the increase of confining pressure, the peak strength and residual strength of sandstone increase, the plastic deformation at pre-peak stage increases, and the stress drop rate at post-peak stage decreases, the overall mechanical characteristics of sandstone specimen vary from brittle failure to ductile failure.
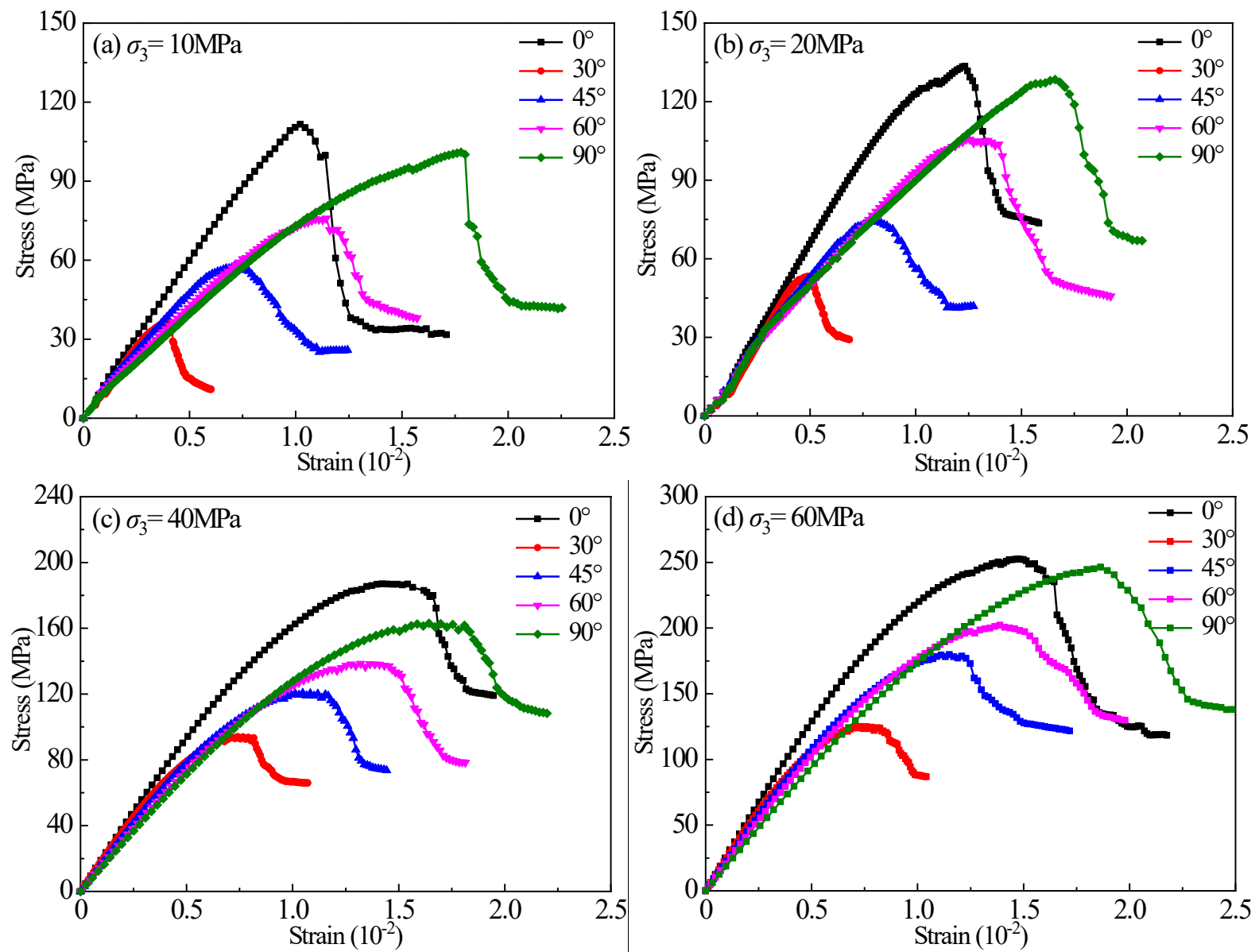

Fig. 21. The stress-strain curves of sandstone specimens with different confining pressures and BP angles

The mechanical properties and brittleness index of sandstone specimens under different confining pressures were obtained from the stress-strain curves and plotted in Fig. 22. As can be seen from Fig. 22a, there is a positive correlation between confining pressure and the peak strength of sandstone. Under different confining pressures, the peak strength first increases and then decreases with the increase of BP angle, and it reaches its minimum value at a BP angle of $30^{\circ}$. From Fig. $22 \mathrm{~b}$, with the increase of confining pressure, the elastic modulus of sandstone with different BP angles decreases. With the increase of BP angle, the variation degree of elastic modulus becomes smaller. Fig. 22c shows the variation of brittleness index $B I$ with confining pressure and BP angle. The brittleness anisotropy decreases with the increase of confining pressure. With the increase of confining pressure, the degree of brittleness anisotropy of sandstone weakens, and sandstone transforms from anisotropy to isotropy. 

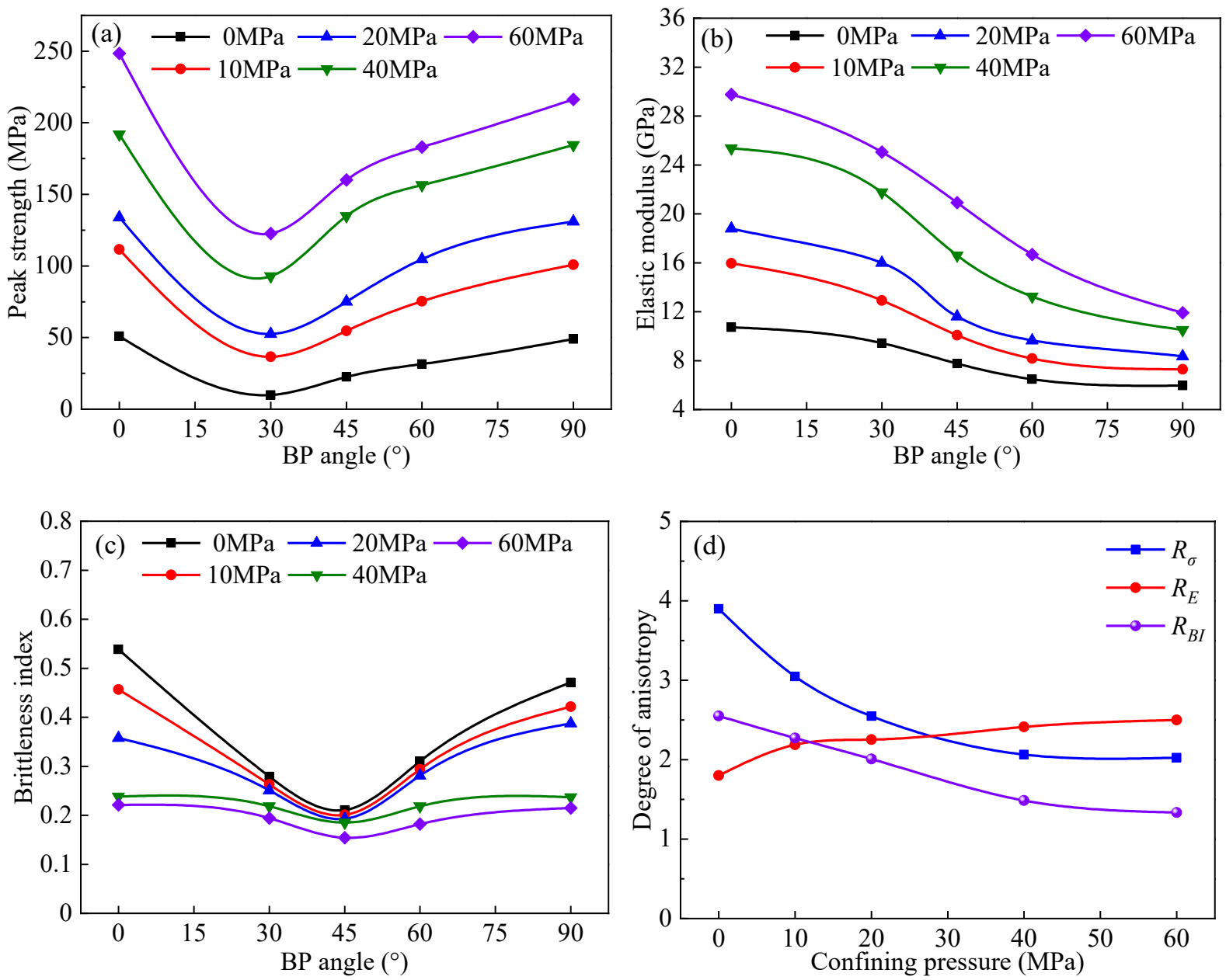

Fig. 22. (a) Peak strength, (b) elastic modulus, and (c) brittleness index of sandstone specimens under different confining pressures and BP angles

Fig. 22d illustrated the effect of confining pressure on the degree of anisotropy of deep laminated sandstone. Both BP angle and confining pressure have significant effects on the degree of anisotropy of mechanical properties and brittleness index. The anisotropic degrees of peak strength and elastic modulus show an opposite trend with the variation of confining pressure. The $R_{E}$ increases with the increase of confining pressure due to the microcracks and pores in sandstone specimen are compacted under confining pressures, while $R_{\sigma}$ decreases with the increase of confining pressure since the confining pressure inhibit the failure of BPs, and the fracture mechanism of sandstone changes. When the confining pressure is low (0MPa), the $R_{B I}$ is 2.55 . With the increase of confining pressure, the $R_{B I}$ gradually decreases and tends to be stable. The inhibition effect of confining pressure on the anisotropy of laminated sandstone is obvious. The microcracks of sandstone are compacted under increasing confining pressures, thus their influence on the brittleness anisotropy weakens, and the influence of BP characteristics on the brittleness anisotropy dominates. For sandstone formations with high in-situ stresses, ignoring the anisotropy of mechanical properties and brittleness may cause large errors in the fracturing treatment design and analysis.

\subsection{AE characteristics of anisotropic sandstone}

Acoustic emission (AE) is a widely used technique to investigate the fracture characteristics of rock (Mogi $\mathrm{K}$ 1985, Ma et al., 2020). In this work, the AE characteristics of anisotropic sandstones under compressions were numerically simulated using the RFPA3D model. To investigate the effects of rock brittleness on AE characteristics, the $\mathrm{AE}$ counts and accumulative $\mathrm{AE}$ counts under different conditions were summarized. Figs. 23 
and 24 plotted the $\mathrm{AE}$ counts, accumulative $\mathrm{AE}$ counts, and the corresponding stress-strain curves of laminated sandstone specimens under different confining pressures and BP angles. The confining pressure and BP angle have an evident effect on the AE mode. From Figs. 23 and 24, the evolution of AE characteristics can be categorized into three types, which are defined as rapid fracture type, plastic fracture type, and stable fracture type (Zhang et al., 2018).

(1) Rapid fracture type. This type is represented by the AE mode under the conditions of $\varphi=0^{\circ}$ and $\sigma_{3}=$ $0 \mathrm{MPa}$, as shown in Figs. 23a and 24a. A slight amount of AE events appear at the initial stage of loading, resulting in very slow growth of the accumulative AE counts curve. Then a sudden increase in AE counts occurs when axial stress reaches its peak value and the accumulative AE counts curve shows a rapid rise. During the post-peak stage, a slight amount of AE events appear. The accumulative AE counts curve shows steady growth first and then increases rapidly at the peak stress. The rapid fracture type curves represent the strong brittleness characteristics of sandstones.

(2) Plastic fracture type. This type is represented by the AE mode under the conditions of $\varphi=45^{\circ}$ and $\sigma_{3}=$ $60 \mathrm{MPa}$, as shown in Figs. 23b and 24c. A considerable amount of AE events occur at the initial stage of loading, and the $\mathrm{AE}$ accounts increase continuously and reach the maximum value at the peak stress. The AE activity is still intense after the peak stress since many AE events occur during the post-peak stage. The accumulative $\mathrm{AE}$ counts curve presents a gentle increase without sudden changes, indicating an obvious plastic fracture. The plastic fracture type curves represent the weak brittleness characteristics of sandstones.

(3) Stable fracture type. This type is represented by the AE mode under the conditions of $\varphi=60^{\circ}$ and $\sigma_{3}=$ $20 \mathrm{MPa}$, as shown in Figs. 23c and 24b. At the initial stage of loading, a small amount of AE events occur. The AE counts increase gradually as the axial stress increases, and reach the maximum value at the peak stress. During the post-peak stage, the AE activity remains steady. Compared with the characteristics of the rapid fracture type, the $\mathrm{AE}$ counts curve presents more apparently $\mathrm{AE}$ characteristics during the pre-peak stage. The accumulative AE counts curve shows steady growth throughout the failure process. The stable fracture type curves represent the transition of failure characteristics between brittle and ductile sandstones.

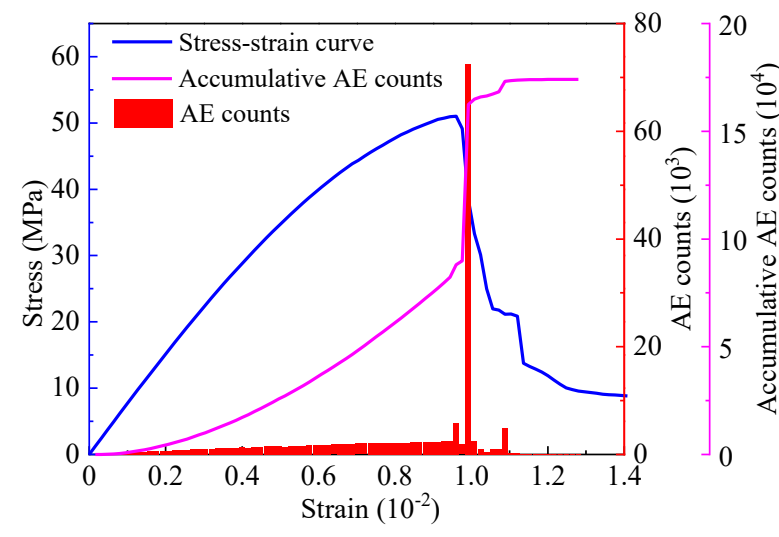

(a) $\varphi=0^{\circ}$

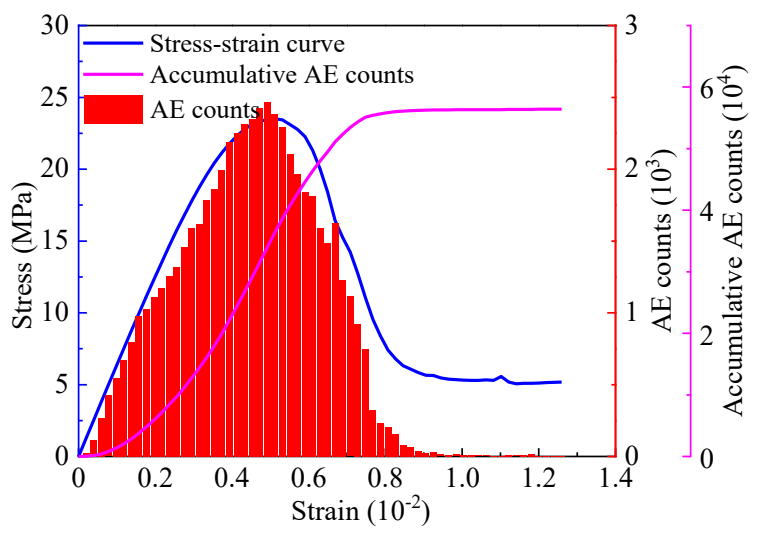

(b) $\varphi=45^{\circ}$ 


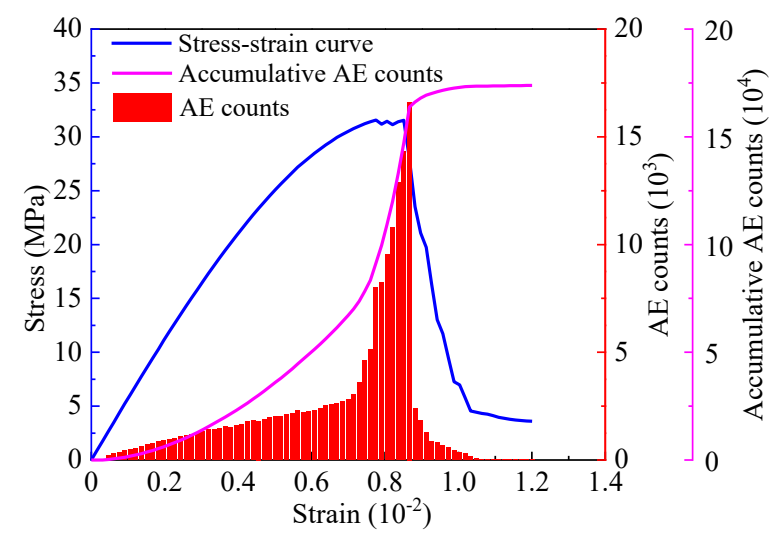

(c) $\varphi=60^{\circ}$

Fig. 23. AE counts-strain curves of laminated sandstone specimens under different BP angles

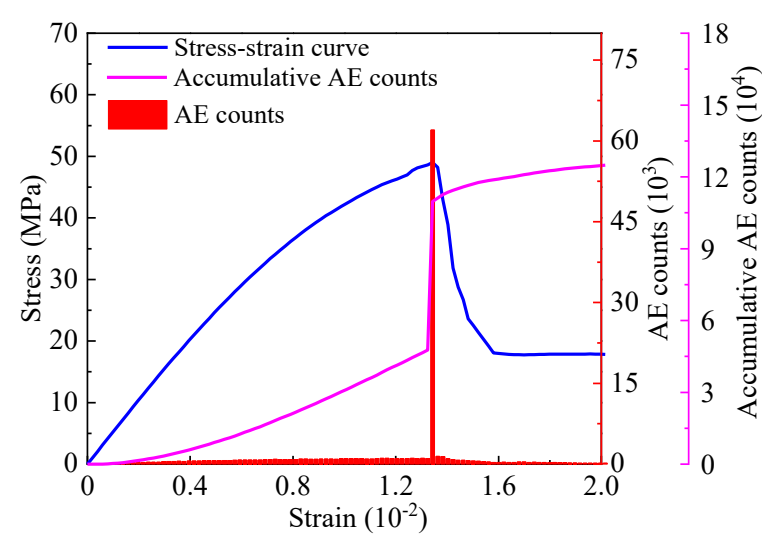

(a) $\sigma_{3}=0 \mathrm{MPa}$

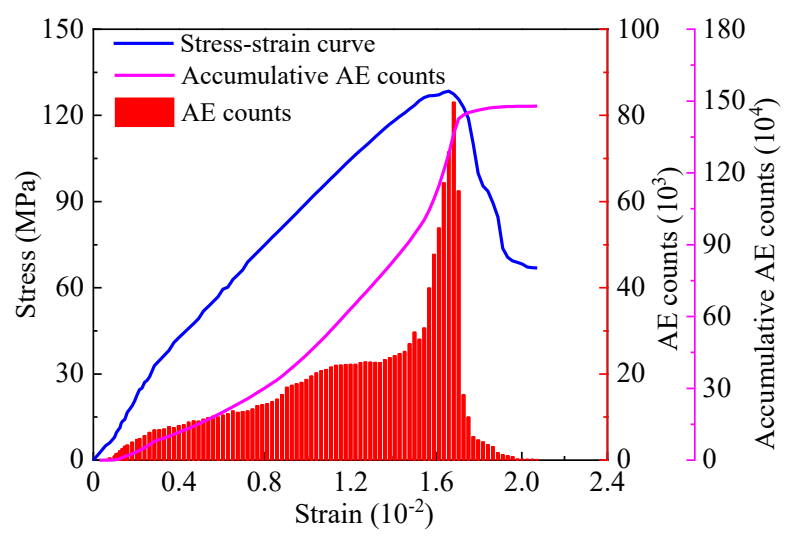

(b) $\sigma_{3}=20 \mathrm{MPa}$

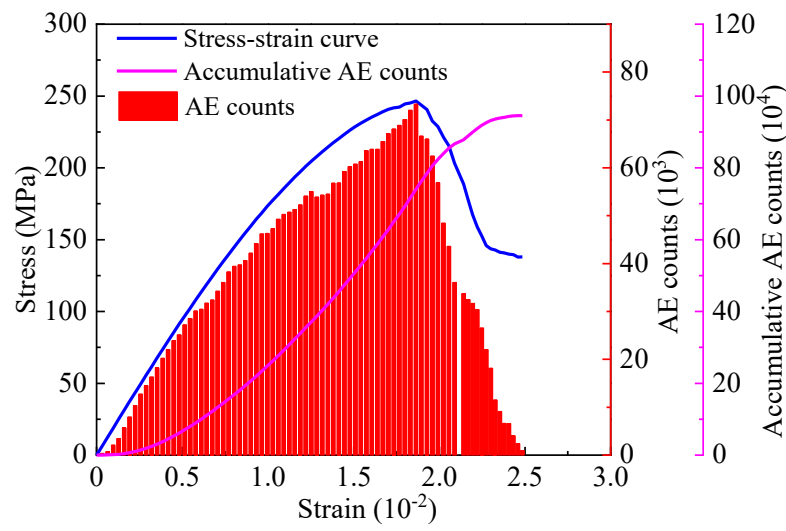

(c) $\sigma_{3}=60 \mathrm{MPa}$

Fig. 24. AE counts-strain curves of laminated sandstone specimens under different confining pressures

For laminated sandstones with different BP angles, the AE counts curves were of the rapid fracture type for $\varphi=0^{\circ}$ and $90^{\circ}$, and of the plastic fracture type when $\varphi=30^{\circ}$ and $60^{\circ}$ and showed characteristics of stable fracture type for $\varphi=45^{\circ}$. The AE mode was affected by the anisotropy of rock brittleness. The evolution model of $\mathrm{AE}$ counts transformed from rapid fracture type into stable fracture type when the $\sigma_{3}$ increases from 0 to $20 \mathrm{MPa}$, and presented plastic fracture type when the $\sigma_{3}=60 \mathrm{MPa}$. This phenomenon indicated that the sandstone brittleness decreases gradually with the increase of confining pressure. The brittleness characteristics reflected by the evolution of the $\mathrm{AE}$ counts under different conditions are consistent with the calculated brittleness index $B I$, indicating that the $\mathrm{AE}$ mode during rock failure is closely related to rock brittleness. The AE modes in high, intermediate, and low brittleness zones are rapid fracture type, stable fracture type, and plastic fracture type, respectively. 


\section{Discussion}

In the process of deep laminated sandstone exploitation, a deep understanding of mechanical properties and brittleness characteristics is crucial for fracability evaluation and fracturing treatment design. Due to the effect of sedimentation and stress environment, the cementation degree of mineral particles and the distribution of microcracks vary along the BPs during sandstone diagenesis, resulting in anisotropy in mechanical properties. The BPs, microcracks, and external loadings may significantly affect the mechanical behavior and stress-strain response of sandstone, thus affecting its brittleness. Therefore, the influence of anisotropy on mechanical properties and brittleness of sandstone formations should be fully considered in the process of perforation interval selection, wellbore trajectory design, and fracturing treatment optimization. To ensure the wellbore stability, the wellbore deviation should be reasonably designed according to the BP dip angle in the sandstone formations. When the wellbore axis is perpendicular or parallel to BPs, the sandstone possesses higher peak strength, which is beneficial to the wellbore stability. The brittleness and fracability evaluation of deep laminated sandstones with developed BPs should consider their anisotropic characteristics. The brittleness index of sandstone at $\varphi=0^{\circ}$ and $90^{\circ}$ is larger than that of other BP angles, in other words, when the perforation angle is vertical or parallel to BPs, the sandstone is more brittle, which is more conducive to the formation of complex fracture networks. In the actual fracturing design, the BP density, dip angle, and confining pressure should be comprehensively considered to make a reasonable evaluation of the sandstone brittleness.

The energy-based brittleness index can better reflect the brittleness characteristics during the rupture process of anisotropic sandstone since it can effectively characterize the stress-strain and damage evolution information during the pre-peak and post-peak stages. From the aspect of energy evolution, rock damage and failure is essentially driven by the transformation of strain energy. Brittle rocks often exhibit energy characteristics including less dissipated energy and more accumulated elastic energy at pre-peak stage, and violent and thorough release of elastic energy to maintain the post-peak rupture with little additional energy. The detailed analysis and reasonable integration of pre-peak and post-peak stress-strain features and accurate determination of residual stress point are crucial to brittleness evaluation. The brittleness index proposed in this work provides a reliable approach for sandstone brittleness estimation, which regards the energy characteristics of pre-peak and post-peak stages as a whole process and can characterize the effect of confining pressure and BP geometry on sandstone brittleness. Whether it can be used as a universal index for evaluating the brittleness of other rock types needs further study. Since the deep laminated sandstones are difficult to be processed into laboratory samples due to the existence of BPs, the numerical modeling technique provides a valuable insight into the brittle/ductile failure behavior of anisotropic sandstones. Although laboratory tests can obtain relatively accurate mechanical properties and brittleness indices, it can only give the properties at some specific points, while geophysical methods can provide a longitudinally continuous distribution of the sandstone properties, which is more applicable. In future work, we plan to combine the brittleness index with geophysical methods (e.g. logging data and surface seismic data) and establish a more universal brittleness estimation approach.

\section{Conclusion}

In this study, the anisotropy of mechanical properties and brittleness characteristics of laminated sandstones has been investigated based on experimental results and numerical simulations. The following conclusions can be drawn.

(1) The rock brittleness is weakened by the dissipated energy at the pre-peak stage and strengthened by the dissipated energy at the post-peak stage. The stronger brittleness involves: (a) rock has more elastic energy storage capacity and less dissipated energy, and little damage occurs at the pre-peak stage; (b) rock rupture is more relied on the released elastic energy, instead of extra energy; (c) the elastic energy is released more rapidly and completely, and damage evolves rapidly at the post-peak stage. The capabilities of storing elastic energy at 
the pre-peak stage and characteristics of self-sustaining failure at the post-peak stage are closely related to rock brittleness.

(2) A new brittleness index $B I$ was proposed based on energy transformation and damage evolution of complete stress-strain curves. It can characterize the effects of BP geometry and confining pressure on sandstone brittleness, and also comprehensively considers the mechanical characteristics of sandstone during the pre-peak and post-peak stages. Moreover, it possesses sufficient physical meaning and is capable of quantifying the whole range from ductility to brittleness in a continuous and monotonic scale from 0 to 1 . Its reliability and accuracy were validated with the experimental results of sandstone specimens under various confinement levels and BP angles.

(3) The use of numerical simulations with the RFPA3D model was an effective method to reproduce the brittle/ductile failure behavior of rock specimens with BPs and confining pressures. The numerical model provided an alternative tool to analyze the mechanical behavior, brittleness anisotropy, and AE characteristics of deep laminated sandstones.

(4) The anisotropy of mechanical properties and failure modes of deep laminated sandstones is jointly affected by BP angle, BP density, and confining pressure. With the increase of BP angle, the elastic modulus of sandstone decreased, while the peak strength decreased first and then increased. The elastic modulus and peak strength of laminated sandstones decrease with the increasing BP density, while increase with the increasing confining pressure. The single shear failure mode represents low brittleness, corresponding to the sandstone specimen at $\varphi=30^{\circ}, 45^{\circ}$, and $60^{\circ}$. The multi-longitudinal splitting mode represents high brittleness, corresponding to the sandstone specimen at $\varphi=0^{\circ}$. The combined failure mode of tension and shear represents intermediate-high brittleness, corresponding to the sandstone specimen at $\varphi=90^{\circ}$.

(5) The sandstone brittleness decreases with increasing confining pressure and is significantly affected by the BP angle and BP density. When the BP angle increases, the sandstone brittleness shows a U-shaped variation of high value on both sides and low value in the middle. The sandstones with BP angles of $0^{\circ}$ and $45^{\circ}$ have the highest and lowest brittleness, respectively. Moreover, the degree of anisotropy of mechanical properties and brittleness index of sandstone is significantly affected by the confining pressure and BP density. The AE counts curves can be categorized into three types. The rapid fracture type is characterized by steady growth first and then sudden growth and represents high brittleness. The plastic fracture type presents a gentle increase without sudden changes, representing low brittleness. The stable fracture type is the transition between rapid fracture type and plastic fracture type. The influence of mechanical anisotropy should be given full consideration in the process of sandstone brittleness evaluation and wellbore stability analysis.

\section{Reference}

Ai, C., Zhang, J., Li, Y.W. 2016. Estimation criteria for rock brittleness based on energy analysis during the rupturing process. Rock Mech. Rock Eng. 49, 4681-4698.

Ai, C., Zhang, J., Li, Y.W., Zeng, J., Yang, X.L., Wang, J.G., 2016. Estimation criteria for rock brittleness based on energy analysis during the rupturing process. Rock Mech. Rock Eng. 49, 4681-5698.

Barton N., Quadros E., 2015. Anisotropy is everywhere, to see, to measure, and to model. Rock Mech. Rock Eng., 48(4): $1323-1339$.

Chang, X., Shan, Y., Zhang, Z., et al. 2015. Behavior of propagating fracture at bedding interface in layered rocks. Eng Geol. 197: 33 - 41.

Chen, Z., He, C., Ma, G., et al. 2019. Energy damage evolution mechanism of rock and its application to brittleness evaluation. Rock Mech. Rock Eng. 52(4): 1265 - 1274.

Cho, J., Kim, H., Jeon, S., Min K., 2012. Deformation and strength anisotropy of Asan gneiss, Boryeong shale, and Yeoncheon schist. Int. J. Rock Mech. Min. Sci. 50:158 - 169 
Deng H., Wang W., Li J., et al. 2018. Experimental study on anisotropic characteristics of bedded sandstone. Chinese J. Rock Mech. Eng. 37: 112 - 120.

Heng, S., Li, X., Liu, X., et al. 2020. Experimental study on the mechanical properties of bedding planes in shale. J. Nat. Gas Sc. Eng. 76: 103161.

Heng, S., Liu, X., Li X., et al., 2019. Experimental and numerical study on the non-planar propagation of hydraulic fractures in shale. J. Petrol. Sci. Eng. 179.

Heng, S., Yang, C., Zhang, B., et al. 2015. Experimental research on anisotropic properties of shale. Rock Soil Mech. 36 (3): $609-616$.

Hucka, V., Das, B., 1974. Brittleness determination of rocks by different methods. Int. J. Rock Mech. Min. Sci. Geomech. Abstr. 17 (10), 389 - 392.

ISRM. The complete ISRM suggested methods for rock characterization, testing and monitoring: 1974-2006 [C]. In: Ulusay R, Hudson JA Prepared by the commission on testing methods. ISRM, Ankara.

Jarvie, D.M., Hill, R.J., Ruble, T.E., Pollastro, R.M., 2007. Unconventional shale-gas systems: the Mississippian Barnett shale of north-central Texas as one model for thermogenic shale-gas assessment. AAPG Bull. 91 (4), $475-499$.

Jin, Y., Wei, Y., Kang, D., et al. 2020. Experimental study and discrete element method modeling of compression and permeability behaviors of weakly anisotropic sandstones. Int. J. Rock Mech. Min. Sci. 134: 104437

Khanlari G., Rafiei B., Abdilor Y., 2015. Evaluation of strength anisotropy and failure modes of laminated sandstones. Arab. J. Geosci, 8(5):3089 - 3102.

Kivi, I.R., Ameri, M., Molladavoodi, H., 2018. Shale brittleness evaluation based on energy balance analysis of stress-strain curves. J. Petrol. Sci. Eng. 167, 1 - 19.

Kuang, Z., Qiu, S., Li, S., et al. 2021. A New Rock Brittleness Index Based on the Characteristics of Complete Stress-Strain Behaviors. Rock Mech. Rock Eng. 54(3): 1109 - 1128.

Lemaitre, J., 1971. Evaluation of dissipation and damage in metals subjected to dynamic loading. In: Proceedings of the International Conference on Mechanical, 1, pp. 15 - 20.

Li, L.C., et al., 2012. Numerical simulation of 3D hydraulic fracturing based on an improved flow-stress-damage model and a parallel FEM technique. Rock Mech. Rock Eng. 45, $801-818$.

Li, M., Yin, G., Xu, J., et al., 2016. Permeability evolution of shale under anisotropic true triaxial stress conditions. Int. J. Coal Geol., 165: $142-148$.

Li, N., Zou, Y., Zhang, S., et al. 2019. Rock brittleness evaluation based on energy dissipation under triaxial compression. J. Petrol. Sci. Eng. 183:106349.

Li, Z., Li, L., Huang B., et al. 2017. Numerical investigation on the propagation behavior of hydraulic fractures in shale reservoir based on the DIP technique. J. Petrol. Sci. Eng. 154.

Lyu, S., Wang, S., Cheng, X., et al., 2020. Natural fractures in soft coal seams and their effect on hydraulic fracture propagation: A field study. J. Petrol. Sci. Eng., 192.

Ma, J., Wu, S., Zhang, X., et al. 2020. Modeling acoustic emission in the Brazilian test using moment tensor inversion. Comput. Geotech. 123: 103567.

Ma, X., Zhou T., Zou Y., 2017. Experimental and numerical study of hydraulic fracture geometry in shale formations with complex geologic conditions." J. Struct. Geol. 98: 53 - 66 .

Meng, F., Zhou, H., Zhang, C., Xu, R., Lu, J., 2015. Evaluation methodology of brittleness of rock based on post-peak stress-strain curves. Rock Mech. Rock Eng. 48 (5), 1787 - 1805.

Mogi, K. 1985. Earthquake prediction. Academic Press, Tokyo.

Munoz, H., Taheri, A., Chanda, E.K., 2016a. Fracture energy-based brittleness index development and brittleness quantification by pre-peak strength parameters in rock uniaxial compression. Rock Mech. Rock Eng. 49, $4587-4606$. 
Nasseri, M., Rao, K., Ramamurthy, T., 2003. Anisotropic strength and deformational behaviour of Himalayan schists. Int. J. Rock Mech. Mining Sci. 40(1): 3 - 23.

Niandou, H., Shao, J.

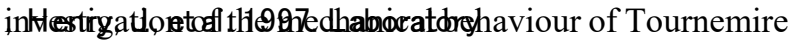
shale. Int. J. Rock Mech. Min. Sci. 34: 3 - 16.

Ramamurthy, T., 1993. Strength and modulus responses of anisotropic rocks. In: Hudson JA (ed) Comprehensive rock engineering, vol. 1. Fundamentals. Pergamon Press, Oxford, pp $313-329$.

Rickman, R., Mullen, M.J., Petre, J.E., Grieser, W.V., Kundert, D., 2008. A practical use of shale petrophysics for stimulation design optimization: all shale plays are not clones of the Barnett Shale. In: SPE Annual Technical Conference and Exhibition. SPE-115258.

Rybacki, E., Meier, T., Dresen, G., 2016. What controls the mechanical properties of shale rocks? -Part II: brittleness. J. Pet. Sci. Eng. 144 (1), $39-58$.

Tang, C., Wang, W., et al., 1998. A new approach to numerical method of modelling geological processes and rock engineering problems-continuum to discontinuum and linearity to nonlinearity. Eng. Geol. 49, $207-214$.

Tarasov, B., Potvin, Y., 2013. Universal criteria for rock brittleness estimation under triaxial compression. Int. J. Rock Mech. Min. Sci. 59, 57 - 69.

Tavallali A, Vervoort A. 2013. Behaviour of layered sandstone under Brazilian test conditions:Layer orientation and shape effects. J. Rock Mech. Geo. Eng. 5(5): $366-377$.

Wang, H., Guo, Y., Wang, L., 2017. An experimental study on mechanical anisotropy of shale reservoirs at different depths. Rock and soil Mechanics, 38(9): 2496-2506.

Wasantha PL, Ranjith PG, Shao SS. 2014. Energy monitoring and analysis during deformation of bedded-sandstone: use of acoustic emission. Ultrasonics. 54(1): $217-226$.

Xia, Y., Li, L., Tang, C., et al., 2017. A new method to evaluate rock mass brittleness based on stress-strain curves of class I. Rock Mech. Rock Eng. 50 (5): 1123 - 1139.

Xie, H., Li, L., Peng, R, et al., 2009. Energy analysis and criteria for structural failure of rocks. J. Rock Mech. Geo. Eng. 1, $11-20$.

Zhang, D., Ranjith, P.G., Perera, M.S.A., 2016. The brittleness indices used in rock mechanics and their application in shale hydraulic fracturing: a review. J. Petrol. Sci. Eng. 143, $158-170$.

Zhang, J., Ai, C., Li, Y., et al. 2018. Energy-based brittleness index and acoustic emission characteristics of anisotropic coal under triaxial stress condition. Rock Mech. Rock Eng. 51: $3343-3360$

Zhao, Y., Yang, H., Chen, Z., et al., 2019. Effects of jointed rock mass and mixed ground conditions on the cutting efficiency and cutter wear of tunnel boring machine. Rock Mech. Rock Eng. 52: 1303 - 1313.

Zou, Y., Ma, X., Zhou, T. et al., 2017. Hydraulic Fracture Growth in a Layered Formation based on Fracturing Experiments and Discrete Element Modeling. Rock Mech. Rock Eng. 50: 2381 - 2395.

\section{Declaration of interests}

The authors declare that they have no known competing financial interests or personal relationships that could have appeared to influence the work reported in this paper.

\section{Acknowledgment}

This work was conducted with support from the National Natural Science Foundation of China (grant NOs. 51879041 and 51761135102), the National Science and Technology Major Project of China (Grant No. 2017ZX05072), and the Fundamental Research Funds for the Central Universities (No. N180105029). The authors express their sincere thanks to the reviewers for their helpful comments and suggestions for improving this paper. 